REVUE DE L'INSTITUT

FRANÇAIS D'HISTOIRE EN ALLEMAGNE

\section{Revue de l'IFHA}

Revue de l'Institut français d'histoire en Allemagne

\title{
L'aigle : évolution d'un symbole en Allemagne et en Pologne. Le cadre de la recherche : les lieux de mémoire germano-polonais
}

\section{Damien Thiriet}

\section{(2) OpenEdition}

\section{Journals}

Édition électronique

URL : https://journals.openedition.org/ifha/254

DOI : 10.4000/ifha.254

ISSN : 2198-8943

Éditeur

IFRA - Institut franco-allemand (sciences historiques et sociales)

\section{Édition imprimée}

Date de publication : 1 janvier 2010

Pagination : 209-246

ISSN : 2190-0078

\section{Référence électronique}

Damien Thiriet, «L'aigle : évolution d'un symbole en Allemagne et en Pologne. Le cadre de la recherche : les lieux de mémoire germano-polonais », Revue de l'IFHA [En ligne], 2 | 2010, mis en ligne le 01 février 2013, consulté le 15 février 2023. URL : http://journals.openedition.org/ifha/254 ; DOI : https://doi.org/10.4000/ifha.254

\section{Ce document a été généré automatiquement le 29 septembre 2020.}

Tous droits réservés 
L'aigle : évolution d'un symbole en Allemagne et en Pologne. Le cadre de la recherche : les lieux de mémoire germano-polonais

\author{
Damien Thiriet
}

Le programme de recherche «Deutsche und polnische Erinnerungskulturen in der longue durée. Ein neuer Ansatz in der Geschichte der deutsch-polnischen Beziehungen " s'inscrit dans une nouvelle orientation de la recherche sur les lieux de mémoire, attachée à une perspective régionale ${ }^{1}$ ou transnationale ${ }^{2}$. Lancé en septembre 2006, il doit donner lieu à publication courant 2011. Ses concepteurs ${ }^{3}$ ont insisté sur la dimension collective du projet $^{4}$. La réflexion méthodologique ${ }^{5}$, d'autant plus nécessaire que les Polonais entendent par « lieu de mémoire » (miejsce pami'ci) des sites où a coulé le sang de patriotes polonais ${ }^{6}$, s'est notamment appuyée sur les critiques de Moritz Csáky. Celles-ci portent sur l'enfermement des lieux de mémoire dans une unique dimension nationale, ce qui redonne un second souffle à l'historiographie nationale du XIX $\mathrm{X}^{\mathrm{e}}$ siècle ${ }^{7}$. L'étude des lieux de mémoire ne saurait oublier que la nation n'est pas un principe unique de construction sociale. Par ailleurs, ces études doivent prendre plus de profondeur historique, dans la mesure où la mémoire (Erinnerung) actualise sans cesse ce dont on se souvient (Gedächtnis) pour l'adapter aux besoins du moment ${ }^{8}$. Les codes culturels qui président à l'érection d'un monument peuvent disparaître, lui donnant une valeur radicalement différente de sa signification initiale 9 .

Les concepteurs du projet ont pris en compte d'autres critiques formulées à l'égard des précédents Lieux de mémoire, relatives à la composition des équipes de chercheurs ${ }^{10}$ ou au choix des sujets ${ }^{11}$. Certes, la plupart des entrées retenues ${ }^{12}$ renvoient aux antagonismes nationaux construits au XIX ${ }^{\mathrm{e}}$ siècle et exacerbés durant les décennies suivantes, avec une place particulière pour la Seconde Guerre mondiale («bataille de Tannenberg/ Grunwald $»^{13}$; «Bismarck»; «SS»; «Monte Cassino»; «Verlorene Heimat/Ziemie 
odzyskane»; "Volksdeutsche»; "Warschauer Aufstand», etc.). Le projet inclut néanmoins d'autres perspectives: le communisme, («Marx; «1989: Mauerfall und runder Tisch $»^{14}$; «Stasi \& Ubecja »; « Friedensfahrt»; « Maluch \& Trabi \& Käfer »), la Shoah $^{15}$ («Holocaust ; « Auschwitz; «SS »; « Maksymilian Kolbe »; « Edith Stein »,..), la mémoire régionale («Breslau»; «Danzig; «Ostpreussen/Warmia i Mazury»; «Lodsch »; « Kaschuben », « Annaberg »,...), la vision de soi et de l'étranger (« Türkei », Russland », « Amerika », « Frankreich », « Europa »; « Mitteleuropa \& Intermarium »,...), la culture («Beethoven \& Chopin»; «Polish Jazz»; «Nationale Dichter \& Wieszcz: Goethe \& Mickiewicz»; " Heine \& Tuwim »,...) la religion (" Martin Luther \& Matka Boska»; «Bonifatius \& Heiliger Adalbert»; «Maksymilian Kolbe»; «Edith Stein»; « Wir sind Papst \& Nasz Papie"16 »,...), le sport («Das Wunder von Bern 1954 \& Wembley $1973 »)$ ou la place de la femme (« Friedensfahrt»; «KKK \& Mutter Polin»). La liste est loin d'être exhaustive, d'autant que ce regroupement a quelque chose d'artificiel, une même entrée pouvant aborder plusieurs thématiques.

Quelques entrées, comme « August der Starke » ou « Thorner Blutgericht » peuvent être considérées comme des « lieux de mémoire refroidis ». Ils ont perdu de leur intensité, ont connu le passage de la mémoire à l'oubli, en attendant une éventuelle réactivation. Ce souci de prendre en compte les va-et-vient ne ressort pas seulement du choix des entrées. Les auteurs ont été invités à plusieurs reprises à prendre en compte les pertes et résurgences de mémoire lors de la rédaction de leurs articles. L'innovation la plus marquante du projet est cependant celle de lieux de mémoire parallèles. Il s'agit de référents distincts, mais remplissant une fonction analogue dans la culture mémorielle des deux sociétés: le prince Eugène et Jean Sobieski (guerriers défenseurs de la Chrétienté à l'époque moderne) ou le « coup de poignard dans le dos » et la confédération de Targowica ${ }^{17}$ en sont de bons exemples.

Ces thèmes impliquent une approche fonctionnelle du sujet, que mettent en pratique les recherches sur les deux symboles nationaux que sont l'aigle (noir) allemand et (blanc) polonais. Compte tenu de la difficulté de séparer symbole et mémoire, nous nous intéresserons avant tout aux processus d'actualisation des représentations entourant l'aigle. Les sources historiques étudiées mobilisent avant tout un corpus visuel assez vaste, évoluant au fil des époques. Deux catalogues d'exposition permettent heureusement de faire le point sur l'historiographie récente du sujet, tout en fournissant de nombreux exemples. Les cérémonies des 700 ans du blason Aigle Blanc, autrement dit de l'aigle polonais, en 1995, ont donné lieu en effet à une exposition ${ }^{18}$ et à un colloque ${ }^{19}$. Ces travaux ont permis d'aboutir à une première synthèse, complétée depuis, pour les époques médiévales et modernes, par la thèse d'Alexandra Jaworska ${ }^{20}$. Le sujet était, lui, plutôt délaissé par l'historiographie germanique, à l'exception notable du changement de sceau impérial de $1433^{21}$. La thèse de Johannes Enno Korn ${ }^{22}$ demeure, de ce fait, incontournable, mais elle reste trop légère pour faire office d'autre chose que d'une introduction. De même, pour l'époque moderne, les publications consacrées aux symboles allemands émanent plutôt de juristes ${ }^{23}$. L'intérêt récent des historiens pour les usages symboliques du pouvoir a cependant renouvelé l'historiographie du sujet. On attend toujours une synthèse qui en exploite les acquis, mais ceux-ci ont été intégrés dans le catalogue de l'exposition organisée à l'occasion des 200 ans de la chute du Saint-Empire ${ }^{24}$. De même, l'exposition «Flagge zeigen? " organisée par la Stiftung Haus der Geschichte der Bundesrepublik Deutschland offre l'ébauche de synthèse sur les symboles nationaux allemands qui faisait défaut, surtout pour la période d'après-guerre ${ }^{25}$. 
Des visites de terrain et une analyse systématique des timbres-postes produits en Pologne et en Allemagne sont venues compléter les matériaux collectés en bibliothèque. Les timbres offrent en effet plusieurs avantages : ils sont conçus par des institutions étatiques en vue d'une diffusion massive. Ce sont donc des supports privilégiés pour transmettre une vision du pays. Les timbres sont par ailleurs catalogués ${ }^{26}$, ce qui permet de disposer d'échantillon exhaustif en vue d'une étude à la fois quantitative et qualitative des éditions de timbre-postes ${ }^{27}$.

\section{L'aigle devient symbole}

La symbolique aquiline n'est pas apparue dans le même contexte dans les espaces polonais et germaniques, même si elle servit dans les deux cas à propager une idéologie du pouvoir auprès d'élites politiques restreintes. Le recours à l'aigle s'inscrivait dans le projet ottonien de restauration impériale. Il suggérait en effet une continuité historique avec l'empire romain. La « Croix de Lothaire » est emblématique de cette démarche. Cette commande d'Otton III (roi en 983, empereur de 996 à 1002), attaché à diffuser l'idée d'une «renovatio imperii Romanorum» était censée provenir du trésor de Lothaire II, mort en 869. Elle faisait office de trait d'union entre les Ottoniens, les Carolingiens et Rome. Le profil de Lothaire, au pied de la croix, et surtout le camée d'Auguste, à la croisée des deux branches, y occupent des positions stratégiques. Auguste y tient un sceptre surmonté d'un aigle. Une démarche similaire animait sans doute Thietmar de Merseburg lorsqu'il affirmait, à la même époque, que l'aigle de bronze coiffant le toit du palais d'Aix-laChapelle remontait à Charlemagne ${ }^{28}$.

Cette fonction impériale hissa rapidement l'aigle au rang de symbole repris par les différents souverains, passant d'une dynastie à l'autre. Conrad II introduisit un aigle dans le sceau impérial en 1029, une iconographie qui resta en usage jusque $1106^{29}$. L'aigle disparut alors du sceau impérial, mais il devint l'emblème des troupes impériales, qui avaient repris le modèle des aigles romaines. Les Hohenstaufen firent beaucoup pour diffuser ce symbole. En 1158, les Milanais durent s'engager à coiffer leur cathédrale d'un aigle en signe de soumission à l'empereur ${ }^{30}$. L'apparition de l'aigle dans les blasons des princes impériaux confirmait son usage en signe de reconnaissance d'une suzeraineté ${ }^{31}$. Il fut ainsi adopté par Henri II en 1156 pour marquer son allégeance à Frédéric Ier Barberousse, qui venait de promouvoir le margraviat d'Autriche en duchés ${ }^{32}$. À l'inverse, la disparition de ces aigles au XIII ${ }^{\mathrm{e}}$ siècle (exception faite du Brandebourg), témoignait de la volonté de ces féodaux de s'émanciper de la tutelle impériale. En Autriche, le duc Frédéric II adopta ainsi en 1230 les couleurs rouge-blanc-rouge (de gueules à la fasce d'argent) $)^{33}$.

Cette symbolique impériale était bien entendue absente des premiers recours à la figure aquiline dans l'espace polonais. Jan Długosz a certes dressé un lien entre l'oiseau au revers d'un denier de Boleslas le Vaillant et le congrès de Gniezno tenu avec Otton III en 1000, mais cette hypothèse, quoique reprise par de nombreux historiens, est loin de faire l'unanimité. L'identité de l'oiseau n'a pu, en effet, être établie avec certitude ${ }^{34}$. Ce serait de toute façon le seul aigle de la numismatique polonaise avant le denier de Boleslas le Banni représentant vers 1140 un aigle capturant un lièvre. Alexandra Jaworska rappelle que cela ne signifie pas que ce rapace n'avait aucune valeur symbolique polonaise, mais celles-ci n'intéressaient visiblement pas les souverains. Lorsque Boleslas le Banni l'utilisa, c'était pour se parer des vertus du courage triomphant de la lâcheté3 ${ }^{35}$. Dans la Chronique 
polonaise de Vincent Kadłubek, c'est au « signe victorieux de l'aigle » que l'on reconnaît le duc Casimir le Juste lors de la bataille de Brest (1182) : l'emblème avait pris une dimension militaire. Surtout, les débuts de l'héraldique influencèrent les usages de l'aigle.

Le blason impérial (d'or à l'aigle de sable) vit le jour dans les dernières années du XII siècle: Frédéric Ier avait émis une monnaie portant au revers un aigle héraldisé et l'inscription SCVTVM IMPERATORIS ${ }^{36}$. En 1195 ou 1196 fut émis un denier témoignant de la naissance du blason; il portait en avers le buste de Frédéric et FREDERIC REX et au revers un aigle héraldique avec E [ENRICUS] IMPERATOR ${ }^{37}$. La chronique d'Otton de Freysing fut la première à le mentionner, vers $1200^{38}$. Frédéric II fit un large usage de ce blason, qu'il fit sculpter au château d'Ursino, en Catane, ou à Foggia, dans les Pouilles. Ces gestes s'inscrivaient dans une vaste politique symbolique visant à diffuser l'image de l'aigle au-delà de la haute noblesse. Celle-ci décida du choix du nom de l'Aquila ; l'octroi des droits urbains mentionnait le caractère impérial de ce symbole ${ }^{39}$. Le retour à la monnaie d'or, qui n'était plus battue depuis plusieurs siècles dans l'empire et l'Occident chrétien fut l'un des faits les plus marquants de cette propagande impériale. L'Augustale, battue à partir de 1231, jouait sur le registre de la continuité impériale depuis la Rome antique. Cette pièce portait en avers le profil d'Auguste inspiré par celui du camée de la Croix de Lothaire et l'inscription IMP ROM CESAR AVG. Au revers, un aigle de profil (non héraldique) portait la mention + FREDERICVS ${ }^{40}$.

L'adoption des codes héraldiques en Pologne fit que l'aigle, de "signe-symbole ", devint un «signe personnel » (Strofczyski) dans le premier tiers du XIII ${ }^{e}$ siècle. Plusieurs ducs le firent alors figurer sur leur blason, mais toujours en vertu de choix individuels, sans dimension héréditaire ${ }^{41}$. D'autres symboles le concurrençaient, au premier chef le lion. En 1252 ou 1253, le duc de Grande-Pologne Boleslas le Pieux renonça ainsi à l'aigle, au profil du lion ${ }^{42}$. L'aigle ne devint blason dynastique qu'à la fin du XIII ${ }^{e}$ siècle. Les Piast le choisirent en raison de son adéquation au contexte polonais. L'hagiographie polonaise l'associait en effet aux deux saints nationaux. L'une des scènes des portes romanes de la cathédrale de Gniezno représente un aigle veillant sur les reliques de saint Adalbert. On retrouvait le même motif dans la légende de saint Stanislass ${ }^{43}$, canonisé en 1253. Les milieux soutenant la restauration du royaume de Pologne donnèrent une connotation politique à ce culte. La perte de la couronne était présentée comme une punition divine liée au démembrement de l'évêque. L'intercession du nouveau saint devait néanmoins conduire à l'unification des principautés polonaises ${ }^{44}$.

\section{L'aigle, symbole de l'État}

Le changement de blason de Przemysł II en 1290 témoigne du succès de cette symbolique aquiline. Ce duc de Grande-Pologne adopta après la prise de Cracovie un sceau qui témoignait d'une volonté de restaurer le royaume. Deux aigles y figuraient: l'un, sur le gonfanon du prince, faisait office de symbole personnel, en lieu et place du lion arboré jusque-là. L'autre, couronné, symbolisait le royaume à restaurer; le croissant qui le flanquait, symbole des Piast de Silésie, illustrait la légitimité du projet de Przemysł II, désigné héritier par le défunt Henri IV l'Intègre, duc de Wrocław ${ }^{45}$. Przemysł II mena à bien son projet de restauration monarchique. Le sceau de majesté émis en 1295 portait au revers le blason Aigle blanc (de gueules à l'aigle d'argent couronné). L'aigle y était accompagné de l'inscription REDDIDIT IPSE [POTENS V]ICTRICIA SIGNA POLONIS («Le Tout-puissant a rendu aux Polonais les signes victorieux »). Il manifestait la prétention de 
Przemysł II à régner sur tous les Polonais ${ }^{46}$. Le nouveau blason fut repris lors des tentatives suivantes de restauration monarchique, celle, éphémère, de Vencenslas II (1300-1306) puis celle, durable, de Ladislas Petite-Coudée (1320-1333). L'aigle blanc, devenu aigle polonais, orne Szczerbiec, l'épée utilisée lors du couronnement en $1320^{47}$, puis lors des sacres successifs jusque 1764 .

Symbole de la restauration royale polonaise, l'aigle fut également invoqué pour enraciner la restauration impériale de 1312. Le sceau de majesté utilisé par Henri VII après le sacre impérial multipliait les symboles de continuité avec l'empire romain. Des aigles unissaient ainsi l'avers, où le souverain était présenté en Salomon moderne, au revers (un aigle dans une porte romaine). Le chant VI de la Divine Comédie fit également de l'aigle le symbole unissant l'Empire à l'empire romain ${ }^{48}$. Henri VII et, surtout, Louis IV de Bavière renouèrent tant avec la symbolique du pouvoir de Frédéric II que Lieselotte SaurmaJeltsch parle de «relation quasi-totémique » avec l'aigle impérial ${ }^{49}$. Louis IV s'était fait faire, en vue du couronnement impérial, une dalmatique et une écharpe aquilines, qui firent ensuite leur entrée dans le trésor impérial. Ce sont peut-être ces vêtements qu'il porte dans son sceau de majesté. Par rapport à celui d'Henri VII, celui-ci présentait une autre innovation : deux aigles flanquaient désormais le trône aux lions, et un autre ornait la couronne. À partir du sacre de 1328, les partisans de Louis IV firent de l'aigle le symbole d'un empire apte à se défendre, tout en identifiant l'empereur lui-même à l'aigle ${ }^{50}$. Une abondante iconographie appuyait cette thèse. Une sculpture de l'hôtel de ville de Nuremberg le présente grandeur nature dans une composition proche de celle du sceau de majesté. Deux anges y font leur apparition, pour tendre un rideau et toucher sa couronne. Cette sculpture, selon Saurma-Jeltsch, était un véritable mémorial : les anges, empruntés à l'iconographie de saint Louis, signifiaient que Louis IV avait gagné les palmes de la vie éternelle ${ }^{51}$. L'utilisation intensive de l'aigle dans l'héraldique de ses partisans confirme que ses contemporains identifiaient l'aigle au souverain, tout comme ses adversaires. Les Florentins exprimèrent ainsi leur opposition à l'empereur en détruisant des aigles, en les souillant ou en les représentant le cou transpercé ${ }^{52}$.

En Pologne, Casimir III utilisa également l'aigle pour diffuser son message politique dans de plus larges couches de la population. Il donna à l'aigle polonais un nouveau style qui le démarquait clairement des représentations en vigueur en Allemagne, en Bohème ou en Silésie $^{53}$. Aisément identifiable, il représentait la puissance d'un État enfin stabilisé. On le reconnaissait sur les murs de bâtiments royaux, et surtout, encore plus stylisé, au revers du grosz de Cracovie. La couronne entourée de l'inscription KASIMIRVS PRIMUS DEI GRATIA REX POLONIE en avers résumait le programme politique diffusé ainsi à grande échelle : le blason royal illustrait à la fois la puissance du pouvoir, l'unité de l'État et sa continuité, par delà la personne du souverain. La traduction visuelle de cette construction juridique, dite Corona Regni Poloniae, illustrait les clefs de voûte des principales collégiales fondées par Casimir III, par exemple à Wiślica. On y voyait les blasons territoriaux du royaume, avec en place d'honneur les armes de Pologne, qui étaient aussi celles des terres de Cracovie $^{54}$. Les constructions historiques faisaient aussi de l'aigle le symbole de la continuité de l'État. Selon la Chronique de Grande-Pologne, complétée à la fin du XIV siècle, Lech, l'ancêtre des Polonais croisa un soir le nid d'un aigle blanc. La vue de l'oiseau déployant ses ailes devant le soleil couchant, interprétée comme un bon présage l'incita à fonder une ville fortifiée, Gniezno, dont le nom viendrait de gniazdo (nid).

Cette composition fut reprise et perfectionnée par Ladislas II Jagellon. La nouvelle théorie de l'État, dite Rex et Regnum Poloniae, séparait clairement l'État de la personne du 
souverain. Le sceau de majesté de Ladislas $\mathrm{II}^{55}$ représentait ainsi le souverain trônant devant un dais losangé aux aigles polonais et, autour de lui, une chaîne de sept blasons territoriaux tenus par des anges (l'Aigle blanc de la Pologne et des terres de Cracovie, la Lituanie, les terres de Kalisz, de Sandomierz, la Coujavie, les terres de Dobrzyf et la Rus). En choisissant la modeste terre de Dobrzyf, objet d'un contentieux avec les chevaliers teutoniques, Ladislas II défendait aussi sa politique internationale ${ }^{56}$. Cette représentation du royaume fut reprise par ses successeurs, tout en étant adaptée aux besoins géopolitiques du moment. Un siècle plus tard, on retrouvait la Moldavie et la Prusse teutonique, deux États qui avaient rompu leurs liens de vassalité avec la Pologne en 1486 et 1498 parmi les blasons du sceau de majesté d'Alexandre Jagellon $(1502)^{57}$. Les armes de la Pologne-Lituanie, avec sur le tout celles d'Autriche, témoin des prétentions d'Alexandre à l'héritage hongrois des Habsbourg, y avaient pris la place du souverain ${ }^{58}$.

Compte tenu de la spécificité de cet ensemble, les constructions juridico-étatiques impériales étaient autrement plus complexes. Dans ses Economica, Conrad de Megenberg décrivit vers 1350-1352 l'Empire à partir d'armes revisitées : un aigle à deux têtes. Le commentaire spécifiait qu'elles représentaient les laïcs et le clergé, la tradition et le futur ; par ailleurs, la noirceur de l'aigle, clairement détaché sur son fond or, focalisait le regard, illustrant ainsi la capacité de l'empereur à regrouper tous les états sous son autorité. Enfin, l'or évoquait Dieu, les ailes déployées de l'aigle, la passion du Christ et, par analogie, la capacité de l'empereur à souffrir pour accéder au triomphe ${ }^{59}$. Cette métaphore connut une grande postérité, au point d'être parfois utilisée dans une tournure favorable au pape. Dans l'Adamas colluctantium aquilarum de Winand von Steeg, l'aigle symbolisait la primauté papale: ses deux têtes étaient de taille différente, la plus grosse étant tiarée, et la seconde, couronnée ${ }^{60}$.

Sous le règne de Sigismond de Luxembourg, cette figure prit une dimension eschatologique, dans un contexte intellectuel fortement marqué par les constructions alchimiques reposant sur la magie des chiffres et le raisonnement sur plusieurs plans. Dans l'ésotérique Buch der Heiligen Dreifaltigkeit du franciscain Ulmannus (1410-1419) ${ }^{61}$, le blason de l'empereur de la fin des temps illustrait la scène cruciale du couronnement de la Vierge ${ }^{62}$, l'acte unifiant tous les éléments dans la pierre philosophale. Il s'agissait d'un aigle à deux têtes portant un Christ en croix. Le visage du crucifié, à la jonction des deux têtes, formait un troisième chef ${ }^{63}$. Selon Bettina Pferschy-Maleczek, cette perspective eschatologique explique l'adoption de nouvelles armes impériales en $1433^{64}$. Les auréoles entourant les deux têtes couronnées du nouvel aigle illustreraient ainsi l'unification du spirituel et du temporel en la personne de l'empereur. Le nouveau sceau marquait ainsi l'entrée dans un temps nouveau, celui de la réforme de l'Église sous les auspices de l'empereur, ce qui devait ouvrir la route, conformément aux visions johanniques, à la reprise de Jérusalem ${ }^{65}$. L'écu de sable à l'aigle bicéphale d'or que Sigismond fit représenter dans le palais de Nuremberg confirme qu'il se posait en empereur de la fin des temps. Cette vision resta populaire tout au long du XV siècle. En 1479, le Livre de tournoi de Wurtzbourg présenta un blason avec un aigle à trois têtes, décrit comme celui de l'empereur qui reprendrait la terre sainte. Sous Maximilien Ier, on affirmait que l'aigle impérial devait sa couleur au deuil; il redeviendrait doré après la reconquête de Jérusalem ${ }^{66}$.

De ces spéculations naquit une représentation de l'Empire appelée à un grand succès : l'aigle-quarteron (Quaternionenadler). Cette figure, attestée à partir de 1410-1415, reprenait l'idée de l'aigle à deux têtes portant un Christ crucifié. Ses ailes portaient dix 
quarterons de blasons représentant les états impériaux. Dans les faits, cette synthèse était imparfaite, en raison de la non-représentation des ecclésiastiques et du choix arbitraire des représentants de certains états. L'aigle-quarteron nimbé de l'Agrippina d'Henri von Beeck (vers 1469-1471) porte les armes de dix états, des princes aux paysans en passant par les margraves, Landgrafen, Burgrafen, comtes, hommes libres, chevaliers, villes et villages. Le quarteron de paysans (Cologne, Regensbourg, Constance, Strasbourg) a cependant de quoi surprendre ${ }^{67} \ldots$

Cette figure avait cependant le mérite de donner à voir une structure politique fort complexe, si bien qu'elle fut utilisée pendant plus de deux cents ans. La volonté de fidélité au réel se fit assez nettement sentir au XVII ${ }^{e}$ siècle. Dans une gravure de Paul Fürst (1651), l'aigle-quarteron incarnait la translatio imperii : les têtes nimbées portaient les inscriptions « Rome » et «Constantinople », tandis que le nombre de quarterons avait été élargi à 26 , sans compter les armes des princes-électeurs et les nombreux blasons urbains ornant le poitrail ${ }^{68}$. Les cartouches aveugles de la carte de Jan Everetszoon Cloppenburg (1630) montraient toutefois que cette théorie posait déjà problème. La carte de Jan Everetszoon Cloppenburg laissait un certain nombre de cartouches aveugles, parce que l'on ne pouvait les remplir de manière cohérente. Au XVIII ${ }^{e}$ siècle, l'aigle-quarteron était considéré comme un plaisant jeu d'esprit ${ }^{69}$.

L'aigle-quarteron connut également de nombreuses dérivations témoignant de la popularité de cette figure impériale. Ainsi, la gravure Aquila imperialis de Burgkmair ${ }^{70}$ (avant 1508) illustrait l'appel de Conrad Celtis à Maximilien Ier en faveur de la création d'un collegium poetarum et mathematicorum à Vienne. L'aigle-quarteron, bien identifiable aux nimbes portant l'inscription "sacro imperio ", était recouvert de symboles l'érigeant en protecteur des arts et des lettres. Ses deux têtes tenaient les lauriers du poète. Son corps portait la fontaine des neuf muses, abreuvant les sept arts libéraux; à leur pied, le jugement de Paris. L'empereur veillait sur son trône. Les ailes, elles, portaient sept médaillons chacune, symbolisant les sept jours de la Création et les sept arts mécaniques ${ }^{71}$

La métaphore de l'aigle-quarteron s'avéra si utile que les Polonais l'empruntèrent lorsque la perspective de l'extinction de la dynastie des Jagellons relança les débats sur la réforme de l'État. La gravure initiale des Kroniki wszystkiego Âwiata de Marcin Bielski éditées en 1564 représentait ainsi un aigle polonais portant sur ses ailes les armes de SigismondAuguste et de vingt-deux provinces du royaume ${ }^{72}$. En 1588, Tomasz Treter orna l'aigle polonais de médaillons représentant la généalogie mythique des rois de Pologne ${ }^{73}$. Tout comme l'aigle-quarteron en Allemagne, cette iconographie fut reproduite jusqu'aux débuts du XVIII ${ }^{e}$ siècle.

De symbole dynastique, l'aigle était donc devenu un symbole étatique. Dans quelle mesure peut-on cerner sa réception dans les différents groupes sociaux? Les milieux ruraux n'ignoraient pas sa signification: des révoltés d'Alsace prirent pour emblème l'aigle impérial lors de la Guerre des paysans ${ }^{74}$. Il était toutefois plus répandu en milieu urbain, où les entrées solennelles étaient autant d'occasions de l'exposer aux différentes catégories de la population. Le poète Jan Kochanowski interpréta ainsi comme un mauvais présage les mouvements d'ailes de l'aigle décorant un arc de triomphe dressé sur le passage du cortège de couronnement de 1574 : le rapace semblait vouloir «fondre sur le roi $»^{75}$. Le mécanisme agitant les ailes de l'aigle impérial couronnant l'arc monumental érigé à Nuremberg en 1612 pour accueillir Mathias II fit tout autant sensation, tout comme le palan qui suréleva le rapace lorsque l'empereur franchit la porte ${ }^{76}$. 
L'aigle servit surtout de support du patriotisme urbain impérial. De nombreuses municipalités d'Allemagne du Nord et du Brandebourg commandèrent à partir de la fin $\mathrm{du} \mathrm{XV} \mathrm{V}^{\mathrm{e}}$ siècle des statues de Roland. Ces chevaliers portaient le plus souvent un bouclier flanqué des armes impériales. Dans le cas du Roland de Brème érigé en $1404^{77}$, les armes impériales étaient entourées d'une inscription évoquant la défense des libertés octroyées par Charlemagne. La symbolique initiale de ces statues fut vite oubliée ${ }^{78}$, mais la mémoire urbaine y vit une expression de l'autonomie municipale garantie par l'empereur ${ }^{79}$. La défense des libertés urbaines explique la permanence de ce patriotisme au XVII ${ }^{\mathrm{e}}$ siècle, bien après l'apparition des fractures confessionnelles. On produisit ainsi à Nuremberg et, un peu plus tard, à Lübeck ${ }^{80}$ entre 1550 et 1700 de grandes quantités de lustres surmontés par un aigle impérial, dits Winkelarmkronen ${ }^{81}$.

Ce patriotisme impérial animait également les corporations, comme en atteste la forte diffusion, de 1570 à 1750, de chopes de bières émaillées décorées d'aigle-quarterons ( Reichsadlerhumpen). Leur contenance (de 3 à 4 litres) suggère une utilisation lors des fêtes corporatives. Les inscriptions descriptives du type «Le Saint-Empire romain avec l'ensemble de ses parties ${ }^{82}$ furent complétées par des prières et des toasts (par exemple "Que Dieu veille sur le Saint-Empire romain avec l'ensemble de toutes ses parties et le garde ») à partir de la guerre de Trente Ans ${ }^{83}$. Selon Sven Lüken, cette vision corporative du Saint-Empire était avant tout répandue dans les petits États impériaux et chez l'homme du commun ${ }^{84}$.

On retrouve, à une moindre échelle, ce patriotisme corporatif en Pologne-Lituanie. Il avait vraisemblablement les mêmes ressorts, puisque le roi garantissait les privilèges des métiers. L'aigle polonais était d'ailleurs exposé en bonne place, portant les armes de Jean III Sobieski dans l'acte de confirmation des privilèges des marchands ambulants de Cracovie de $1684^{85}$. Plusieurs emblèmes de confréries prirent la forme d'aigles polonais, en particulier à Cracovie, où ce symbole remplissait aussi une fonction locale. Il n'était pas rare que les insignes et trophées des « confréries du coq » (bractwa kurkowe), formées d'artisans astreints à un entraînement au tir pour assurer le cas échéant la défense de la cité, prennent la forme d'un aigle. On a conservé un tel collier de cérémonie de la confrérie de Kościan, en Grande-Pologne, datant du milieu du XV ${ }^{e}$ siècle ${ }^{86}$. Plus connu sont les « coqs » (kury) en forme d'aigle polonais des confréries de Varsovie et Cracovie. Le premier de ces emblèmes fut sculpté par Mikołaj Erler en 1552, le second fut offert par le conseil municipal de Cracovie en $1565^{87}$. Comme en Allemagne, ce patriotisme pourrait avoir comme ressort le fait que le roi était garant des libertés corporatives.

La place marginale des villes dans les institutions de Pologne-Lituanie était peu propice au développement d'un patriotisme urbain analogue à celui du Reich. En revanche, la noblesse polonaise, bénéficiaire exclusive du système politique mis en place en 1569 , développa une forme de patriotisme qui s'exprima, entre autres, par une appropriation de l'aigle polonais. Cherchant à unir une noblesse divisée linguistiquement, elle développa une culture fondée sur le mythe de l'origine sarmate de tous ses membres. Le sarmatisme, qui soulignait les particularités nobiliaires au moyen du vêtement, des rites et des comportements, glorifiait le corps politique de la nation. La gravure réalisée par David Tscherning en ouverture du tome III de l'Orbis Polonus de Szymon Okolski ${ }^{88}$ (1645) en est l'une des visualisations les plus intéressantes. Elle mêlait deux représentations traditionnelles du pouvoir : le roi entouré de ses conseillers et l'aigle ceint par les armes territoriales de la Pologne-Lituanie. En bas, l'allégorie de la Pologne portant la chaîne de la Toison d'or tenait deux poids égaux, OB REMPVE PACI SERVATA et OB ARMIS DEFENSIA 
PATRIA. Devant elle, les insignes du pouvoir reposaient sur une table nappée aux armes de la Pologne-Lituanie et, en liseré, de grands dignitaires. Les deux rangées de nobles, civils à sa gauche et militaires à sa droite, incarnaient les devoirs nobiliaires fondamentaux : la participation à la vie politique et la défense de la patrie. En arrièreplan, la colonne Sigismond et la scène de bataille célébraient le rôle des Vasa. En haut de la composition, un aigle couronné était entouré d'un anneau de blasons territoriaux. Son plumage était recouvert de blasons de la noblesse polonaise. L'aigle était ainsi représenté comme une personnification de la nation politique. Si la composition de Tscherning glorifiait incontestablement le pouvoir royal, son message politique répondait aux attentes des principaux destinataires de l'ouvrage, à savoir la petite noblesse. Le pouvoir royal était en effet célébré pour sa capacité à respecter l'équilibre des institutions ${ }^{89}$.

Plus que cette gravure, qui eut en définitive une diffusion limitée, ce sont les textes littéraires qui témoignent de la popularité de l'assimilation de l'aigle polonais à la nation noble. Suite à la perte de Kamieniec Podolski en 1672, un auteur anonyme publia un chant intitulé Apollon en peine éveille les Polonais insensibles aux larmes devant la perte de la Podolie et de l'Ukraine et leur ordonne de se rendre à Mars pour l'année $1673^{90}$. Ce chant, typique du courant " éveilleur » et dont la popularité ne se démentit pas tout au long du XVIII ${ }^{\mathrm{e}}$ siècle - il fut repris dans de nombreux recueils - faisait de l'aigle sarmate, incarnant la nation nobiliaire, l'une de ses figures essentielles.

«[...] Aigle sarmate, où sont tes éclairs?

Où sont des canons flamboyants le tonnerre?

Où est la volonté de jadis? Où est la vertu des aïeux ? "

Des Lamentations de l'Aigle polonais sur le cavalier héraldique du Grand-Duché de Lituanie $e^{92}$ (1700) aux Lamentations de l'Aigle polonais sur la chute de la patrie ${ }^{93}$ de 1789 , les occasions de se plaindre ne manquèrent pas au XVIII ${ }^{\mathrm{e}}$ siècle ${ }^{94}$. On parlait d'ailleurs de la coalition des aigles noirs contre l'aigle blanc pour désigner les Partages.

Des scènes similaires accompagnèrent la chute de la République des deux nations en 1795 et celle, onze ans plus tard, du Saint-Empire romain germanique. L'emblème des régimes leur succédant vint prendre leur place. À Varsovie, l'aigle prussien remplaça l'aigle polonais sur les bâtiments publics le 20 janvier $1797^{95}$. De même, l'aigle à deux têtes monumental qui ornait l'hôtel de ville d'Augsbourg fut détruit lors de l'annexion de la ville par la Bavière en $1806^{96}$.

\section{Aigle allemand, aigle polonais}

La disparition de la République des deux nations divisa la nation politique. «Finis Poloniae » pensaient les uns, en vertu de la conception géopolitique des Lumières, qui voulait qu'une nation ne puisse exister sans État. Józef Wybicki compara ainsi les Partages à la disparition de Troie ou de Carthage. "La Pologne n'est pas encore morte » rétorquaient d'autres, au nom d'une autre conception de la nation. Dès 1791, Franciszek Salezy Jezierski avait affirmé que la nation était unie par la langue, les us et coutumes. Le principe selon lequel « là où est la langue polonaise, là est la Pologne » devint l'un des slogans des milieux indépendantistes ${ }^{97}$. Parallèlement, la politique d'aristocratisation de la noblesse (distribution de titres de ducs, barons ou comtes) entreprise par les nouveaux souverains profita à une minorité, avant tout aux anciens magnats, tout en entraînant le déclassement d'une foule de petits nobles ${ }^{98}$. Ce processus était en germe dans la constitution polonaise du 3 mai 1791, mais le mécontentement des perdants pouvait 
d'autant plus se retourner contre les nouveaux souverains que certains de ces petits nobles avaient été formés par les institutions réformatrices fondées sous Stanislas Auguste Poniatowski.

L'aigle devint leur signe de ralliement. Sa conversion en symbole militaire avait déjà été amorcée avant 1795. Des uniformes polonais l'arboraient déjà sous la dynastie saxonne, et cela avait été systématisé en 1791. Il ornait également les premières décorations militaires, la croix des confédérés de Bar (aigle sans couronne) et la Virtuti militari (du moins sa version définitive) instaurée après la bataille victorieuse de Zieleniec en 1792. C'est toutefois sous l'influence des uniformes napoléoniens qu'apparut en janvier 1810 la forme définitive de l'aigle militaire polonais, reposant sur un bouclier d'amazone ${ }^{99}$.

Condamné à disparaître des édifices publics, sauf dans le Royaume du Congrès où il était subordonné à l'aigle tsariste, l'aigle symbolisait, par son absence, la non-souveraineté. D'où son retour dès que les circonstances le permettaient. À l'époque napoléonienne, ce fut d'abord l'aigle français que l'on accueillit avec enthousiasme, mais on vit ressurgir assez vite des aigles polonais. Lors des cérémonies du 3 mai 1807, on en hissa sur les bâtiments officiels de Poznan ${ }^{100}$. L'aigle polonais devint l'un des éléments les plus caractéristiques du style décoratif "Grand-duché de Varsovie", tout particulièrement des luminaires. Une nouvelle vague de décoration des bâtiments publics au moyen du symbole national fut observée lors des insurrections nationales ${ }^{101}$. Dans la petite ville de Tarczyf, le chef de la poste exhuma en 1830 l'aigle de la période de Stanislas Auguste, provoquant l'enthousiasme de la population. On vint en cortège le faire bénir par le curé, avant de le fixer à l'hôtel de ville ${ }^{102}$. L'épisode témoigne aussi bien de la ferveur patriotique des milieux urbains - l'un des deux piliers du mouvement national au côté des propriétaires terriens (ziemiaństwo), héritiers de la noblesse de la Rzeczpospolita - que de la charge sentimentale qu'avait acquise l'aigle polonais à la faveur des Partages. « Polonais ! Voici notre aigle, cette terre est la nôtre !", avait-on écrit sur la mairie de Varsovie ${ }^{103}$.

L'aigle figure aussi en bonne place dans l'abondante bijouterie patriotique portée par les insurgés, souvent de la main de femmes de terriens. Le catalogue de l'exposition de 1995 comprend, entre autres, un portefeuille brodé aux armes du gouvernement de 1831 portant l'inscription " pour la liberté de l'aigle polonais et du cavalier lituanien $»^{104}$ et une broche patriotique circulaire de 1861-1862 dans laquelle l'aigle polonais (couronné) est ceint d'une couronne de lauriers et de l'inscription «Dieu sauve la Pologne » complétée de croix ${ }^{105}$. Cette association des registres patriotiques et religieux était caractéristique de toute une veine de la production des années de 1863-1864, plutôt liée aux « blancs » ${ }^{106}$. On produisit même, après 1864 , des aigles tenant la palme du martyre et la croix, ce qui renvoyait aussi bien à l'échec du soulèvement qu'à la théorie de la Pologne «Christ des nations » développée après 1830 dans les milieux romantiques ${ }^{107}$.

Les divisions politiques de la Grande immigration rejaillirent néanmoins sur les questions de symbolique nationale. En 1832, la société démocratique adopta pour étendard l'aigle blanc sans couronne, accompagné de l'inscription «Pologne démocratique LibertéÉgalité-Fraternité». Cette version républicaine fut reprise par l'aile radicale du mouvement national, si bien que les étendards des détachements insurgés permettaient d'identifier leur opinion politique. L'aigle sans couronne fut adopté par les combattants de Cracovie en 1846, par la plupart des détachements de Grande-Pologne en 1848; en revanche, l'étendard de la Légion polonaise combattant en 1848-1849 en Hongrie sous les ordres de Józef Wysocki portait l'aigle couronné sur une face, et la Vierge sur l'autre ${ }^{108}$. De même, lors du soulèvement de 1863-1864, un coup d'œil sur l'aigle des étendards suffisait 
pour savoir si le détachement était «blanc» ou «rouge ». L'aigle sans couronne des armes du gouvernement clandestin, adoptées le 10 mai 1863, n'avait pas, en revanche, de connotation politique. L'écu était d'ailleurs surmonté d'une couronne qui, après de longs débats, avait été préférée à la croix ${ }^{109}$.

L'aigle n'avait pas le même potentiel mobilisateur dans les milieux libéraux et nationaux allemands, d'autant que les puissances de la Sainte-Alliance arboraient l'aigle noir. Contrairement au cas polonais, les questions de drapeau suscitèrent les débats les plus passionnés, dans la mesure où les couleurs noir-rouge-or incarnaient les aspirations des démocrates. Il existait un relatif consensus autour de l'aigle. Lorsque la Confédération germanique dut se doter d'armes pour les besoins des forteresses confédérales, l'aigle noir à deux têtes sans attribut régalien fut adopté sans trop de difficulté. Les protestations des délégués bavarois portaient sur l'existence d'un symbole confédéral, non sur sa forme. Le plénipotentiaire prussien affirma, lui, que «seul le vieil aigle impérial allemand réunit en lui toutes les relations national-allemandes et historiques ${ }^{110}$

Le Printemps des peuples révéla cependant des divergences. Lors du débat du 9 mars 1948, une minorité proposa en vain l'adoption de l'aigle simple, en jouant sur le goût du roi de Prusse pour le Moyen Âge ${ }^{111}$. Cette motion témoignait des progrès d'une relecture du passé allemand amorcée sous le romantisme. La réhabilitation du Moyen Âge s'était alors focalisée sur la figure de Frédéric Ier Barberousse, dont le règne fut réinterprété comme âge d'or de la puissance allemande ${ }^{112}$. Le choix de l'aigle à deux têtes flanqué de l'inscription «Deutscher Bund » lui rallia à l'inverse les libéraux, qui y virent un symbole de la Diète de Francfort. Les armes confédérées y étaient en effet bien visibles, tant sur le baldaquin dressé au-dessus de la tribune que, un étage plus haut, sur le poitrail de la Germania de Philipp Veit ${ }^{113}$.

Cette nouvelle symbolique ne modifia guère le goût des partisans de la solution grandeallemande pour l'aigle à deux têtes. Otto Titan von Hefner exprimait un point de vue dominant chez les conservateurs catholiques lorsqu'il affirmait en ouverture du Siebmacher's Wappenbuch:

«L'empire allemand millénaire s'est achevé en 1806 sous un coup brutal venu de l'extérieur. Néanmoins, l'éditeur se croit tenu de voir, aujourd'hui encore, dans les armes de l'ancien Saint-Empire romain germanique et de ses piliers, les princes impériaux, l'expression fondamentale de la grandeur allemande et de son unité. Il a aussi choisi l'époque où l'Allemagne atteignait le plus haut point de sa puissance, l'époque des sept princes-électeurs »114.

En revanche, dans le camp petit-allemand, le souvenir du Printemps des Peuples renforça le rejet des couleurs noir-rouge-or et accentua les réticences vis-à-vis de l'aigle à deux têtes. Lors des débats passionnés qui agitèrent l'entourage impérial en 1871, l'aigle à deux têtes fut rejeté parce qu'il était trop associé à la Diète de Francfort et à la « reculade d'Olmütz». Le Kronprinz Frédéric, qui entendait instaurer une continuité entre le Deuxième Reich et le Saint-Empire, s'opposa ensuite au chef du bureau héraldique soutenu par l'impératrice, partisan de l'élévation de l'aigle prussien à la dignité impériale. Bismarck, qui souhaitait éviter un débat public, usa de ruse pour imposer l'option du Kronprinz. L'aigle impérial serait celui de l'Empire médiéval, portant les armes de Prusse en poitrine et la couronne d'Othon ${ }^{115}$.

Les armes impériales furent d'autant plus mobilisées pour consolider l'unité allemande que le nouvel État n'avait ni hymne national, ni drapeau (du moins jusqu'en 1892) ${ }^{116}$. Le 
nouvel aigle fut ainsi le seul motif décorant les timbres-postes impériaux jusqu'en 1900. Sous Guillaume II, il servit avant tout à exalter le sentiment national en dressant une continuité avec un passé médiéval et impérial magnifiée ${ }^{117}$. À l'occasion des 25 ans de la proclamation de l'Empire, Guillaume II affirma qu'un «empire universel était né de l'Empire allemand $~^{118}$. La même année fut inauguré le monument du Kyffhäuser, l'un des quatre lieux de mémoire massifs illustrant ce programme idéologique. L'acte de pose de la première pierre en résumait l'idée directrice : "Sur le Kyffhaüser, là où, à en croire la légende, l'empereur Frédéric Barberousse attend le renouveau de l'Empire, se dressera l'empereur Guillaume Barbeblanche, qui a accompli la légende ${ }^{119}$. La gigantesque tour néo-médiévale unissait dans un même axe vertical Fréderic Barberousse endormi sur son trône, la statue équestre de onze mètre de Guillaume Ier en uniforme et l'aigle, trait d'union entre les deux empires. Ce dernier remplit une fonction similaire lors de la restauration du Haut-Koenigsbourg aux frais de Guillaume II entre 1900 et 1908. La forteresse alsacienne devint alors le pendant occidental de la forteresse teutonique de Marienbourg ${ }^{120}$ : un témoin de l'enracinement germanique dans des terres contestées par les Français ou les Polonais. L'aigle de Charles Quint qui surmontait la porte du HautKoenigsbourg fut ainsi coiffé de l'aigle (plus grand) de Guillaume II. De même, un grand aigle armorié, inspiré de l'aigle-quarteron médiéval dominait la nouvelle salle du Kaiser.

L'aigle polonais fut également mobilisé par les élites polonaises pour accompagner la création d'une nation polonaise moderne. Les premiers vers du Catéchisme de l'enfant polonais $^{121}$ de Władysław Bełza (1900) symbolisaient ce vaste effort de création d'une culture nationale :

«-Qui es-tu?

- Un petit Polonais

- De quel signe es-tu?

- De l'Aigle blanc. ${ }^{122}$

L'aigle fut également mobilisé par les artistes qui cherchaient à créer un art national. En créant le «style Zakopane » Stanisław Witkiewicz mélangea art montagnard traditionnel réinterprété et, plus discrètement, symboles nationaux. La poignée de la porte d'entrée de la Villa Koliba (1891-1892), première demeure réalisée dans ce nouveau style, en offre une bonne synthèse : pour y entrer, il fallait actionner une poignée en forme de cannehache montagnarde (czupaga); la serrure, elle, était décorée d'un aigle polonais ${ }^{123}$. De même, les vitraux latéraux de la chapelle en bois de Jaszczurówka (1904-1907) représentaient les rames de Pologne et de Lituanie, accompagnées des Vierges de CZĘstochowa et d'Ostra Brama (Wilno).

La présence de tels symboles dans les édifices religieux n'avait rien d'étonnant. L'Église catholique se posait en effet en protectrice du sentiment national, voire en garante de sa pureté. Le blason polonais ornait ainsi de nombreuses polychromies réalisées aux tournants des XIX et XXe siècles par des artistes de renom, le plus souvent dans le chœur. Citons, entre autres, l'église des franciscains de Cracovie (Stanislas Wyspiafski) ou l'église paroissiale de Sosnowiec (Włodzimierz Tetmajer et Henryk Uziembło). La plus célèbre de ces réalisations était l'aigle monumental peint par Walenty Drapiewski dans la chapelle royale de la cathédrale de Płock. Il était flanqué des armes de Lituanie et de Ruthénie, allusion directe au blason de l'État clandestin de 1863-1864 ${ }^{124}$.

Cette mémoire nationale prit le pas sur celle, démocratique, défendue par l'entourage de Piłsudski. L'aigle sans couronne patronna les sociétés de tir et la première brigade des Légions polonaises. Stanisław Thugutt, ministre de l'Intérieur de la Pologne restaurée, 
publia donc une circulaire ordonnant une « légère modification $»^{125}$ des armes polonaises, la suppression de la couronne. Ce qui était conçu comme une conséquence logique du choix d'institutions républicaines fut attaqué comme une atteinte à l'idée nationale, au point que la mesure ne fut jamais appliquée. En 1922, une affiche électorale attaqua encore Thugutt, si « libéré » du sentiment de polonité qu'il avait voulu priver l'aigle de couronne ${ }^{126}$... Aux yeux de la majorité, l'aigle polonais incarnait avant tout la continuité nationale, au point que le blason officiel adopté en août 1919 reproduisait celui de Stanislas Auguste Poniatowski. Sa modernisation en 1927 suscita de nouvelles joutes, car les milieux conservateurs voyaient dans la disparition de la croix surmontant la couronne une volonté de laïcisation. Il s'agissait plutôt de fidélité historique (la couronne des Jagellon ne portait pas de croix), mais la polémique eut la vie dure, puisque le gouvernement polonais en exil rétablit cette croix en $1956^{127}$.

Loin de ces querelles, l'aigle polonais fut largement plébiscité durant l'Entre-deuxguerres. Il décorait plus de la moitié des modèles de timbres-postes ; il en dominait même la composition dans $35 \%$ des cas $^{128}$. Nombre d'étendards scolaires ou associatifs l'arboraient, souvent de pair avec des symboles religieux. À Łowicz, le fanion du collège et lycée public portait ainsi en avers un aigle polonais stylisé en art déco, et au revers le Christ bon Pasteur ; celui de la section syndicale ZZP (démocrate-chrétienne) des chemins de fer, en avers un aigle polonais se tenant sur une roue avec pelle et pioche entrecroisées et au revers la Vierge de CZĘstochowa ${ }^{129}$.

Les polémiques n'épargnèrent pas l'Allemagne, mais elles eurent un autre enjeu. La République de Weimar, après avoir songé un temps à adopter un monogramme ${ }^{130}$, adopta finalement l'aigle allemand, tout en lui donnant un tour plus pacifique que celui observé depuis une vingtaine d'années ${ }^{131}$. L'aigle décorant la salle plénière du Reichstag avait ainsi les serres fermées ${ }^{132}$. Le Reichskunstwart, institution créée pour veiller sur les emblèmes étatiques, proposa de nombreux projets d'aigles ${ }^{133}$. Le premier, proposé par Karl SchmidtRottluff dans une esthétique résolument expressionniste fut taxé de " perroquet effrayé " 134. Une affiche électorale du DNVP de 1924 exploita d'ailleurs ces critiques : on y voyait un aigle puissant dressé sur les couleurs impériales s'en prendre à un aiglon famélique ceinturé en noir-rouge-or. Malgré ces polémiques, l'aigle restait relativement consensuel, puisque chaque parti, jusqu'aux communistes, en proposa, à un moment ou un autre, sa propre version. Il était loin d'éveiller les passions qui se déchaînèrent autour du drapeau. Ce sont d'ailleurs les couleurs impériales, et non l'aigle, qui sont mises en avant par la plupart des affiches électorales du DNVP comme élément polémique ${ }^{135}$.

L'aigle nazi s'inscrivit dans cette logique nationaliste. Il devait exprimer la force du "Reich de mille ans ». Les sculptures de bronze de sept mètres de haut ornant les tribunes d'honneur de la Luitpoldarena de Nuremberg, haut-lieu des grand-messes du régime, donnaient le ton. Par ailleurs, la récupération de cette figure impériale permettait de rallier les conservateurs sans renoncer au projet révolutionnaire nazi, puisque l'aigle était flanqué de la croix gammée. L'étude des timbres-postes du IIIe Reich montre que l'aigle, présent sur $9,5 \%$ des éditions, fut moins mobilisé que la croix gammée (21,5\%) ou Hitler (12,1\%). À l'exception de deux modèles de 1939 en l'honneur du Reichsberufswettkampf ${ }^{36}$ et d'un timbre de 1941 consacré à la foire de Vienne ${ }^{137}$, toutes les éditions dans lesquelles l'aigle jouait un rôle essentiel datent de 1934-1935 ou 1943-1945. Dans le premier cas, il s'agissait d'une période de consolidation du régime. La croix gammée ne fit son apparition comme élément autonome qu'en avril $1935^{138}$. Auparavant, elle était subordonnée à l'aigle et reléguée au second plan. Dans la série de neuf timbres 
par avion présentant un aigle planant devant le globe terrestre, la croix gammée, sertie dans le soleil, se trouvait cantonnée dans le coin, en haut et à gauche, partiellement masquée par la planète bleue ${ }^{139}$. L'autre composition était d'un même esprit. On y voyait, dans un cartouche oblongue, l'aigle héraldique utilisée sous la république de Weimar ${ }^{140}$ avec l'inscription «Sarre » en surimpression; en bas, au second plan, se levait un soleil avec croix gammée dont on ne voyait qu'une moitié ${ }^{141}$. Par la suite, les symboles exclusivement nazis s'affirmèrent avec force ${ }^{142}$. Entre 1935 et 1943, à une exception près, l'aigle apparut toujours en compagnie de la croix gammée. Rares furent les éditions où il figurait comme élément central de la composition $(1,7 \%)$; il y occupait une place secondaire $(4,3 \%)$ ou n'était qu'un détail $(4 \%)$, le plus souvent sur un uniforme ${ }^{143}$. La nécessité de mobiliser au plus large devant la perspective de la catastrophe finale suscita le retour à une iconographie plus œcuménique. L'aigle allemand sans croix gammée réapparut pour commémorer les 400 ans de l'université Albert ${ }^{144}$, puis en renouant avec l'iconographie traditionnelle de la lutte de l'aigle et du serpent ${ }^{145}$. Enfin, en 1945 , l'édition «Un peuple se lève » présenta, de profil, trois générations d'hommes partant à l'assaut avec des armes de différents types, sous la protection d'un aigle massif prenant son envol 146.

Le dénouement de la Seconde Guerre mondiale changea doublement la donne. En Allemagne et Pologne s'imposèrent trois régimes qui fondaient leur légitimité sur une rupture qui les plaçaient en porte-à-faux avec nombre des citoyens. C'est en RDA que la volonté de faire table rase fut poussée le plus loin. La reprise de l'aigle allemand fut un temps envisagée, puis il fut catalogué parmi les attributs de l'Allemagne réactionnaire. Dans une caricature de 1964 liée aux J.O. - les derniers auxquels sportifs des deux Allemagne participèrent dans la même délégation - Hermann Raum présenta ainsi un dirigeant sportif masquant le maillot rouge du vainqueur, aux armes de la RDA, avec un maillot dont l'aigle était démesurément agrandi. Cette vision n'était pas nécessairement partagée par la population. On peut supposer que celle-ci, comme en RFA, voyait dans l'aigle allemand un symbole positif d'unité.

Lorsqu'en 1965 l'institut Allensbacher sonda la population de RFA en lui demandant quel était le symbole du pays, l'aigle arriva en première position ( $45 \%)$, loin devant le drapeau noir-rouge-or $(26 \%)$ et l'hymne national $(2 \%)^{147}$. Ce sondage illustrait parfaitement le décalage entre la société, qui n'avait pas nécessairement fait son deuil d'un passé nationaliste, et les élites du régime. Celles-ci entendaient éliminer tout ce qui pouvait évoquer le nazisme, tout en dressant des ponts avec la république de Weimar. La déclaration du 17 janvier 1950 sur les armes du pays reprit mot pour mot l'ordonnance d'Ebert du 11 novembre 1919, à ceci près qu' «aigle fédéral » (Bundesadler) remplaçait " aigle impérial» (Reichsadler) ${ }^{148}$. Les efforts pour priver l'aigle de toute connotation agressive furent poussés à l'extrême: l'aigle de plâtre créé par Ludwig Gies pour le Bundestag avait ses serres rentrées vers l'intérieur et des formes si arrondies qu'il fut vite surnommé de "poule grasse» (fette Henne), un sobriquet qui prit une dimension affectueuse avec le temps ${ }^{149}$.

Cette prudence se doublait d'une extrême réticence à exposer tout symbole national: le premier timbre de ce type ne fut émis qu'en 1958 - il s'agissait du revers d'un Deutsche Mark portant l'un des aigles de Weimar ${ }^{150}$ - et il fallut attendre 1971 pour voir un timbre aux couleurs nationales ${ }^{151}$. Toutes ces précautions n'empêchèrent pas les attaques en règle provenant des milieux artistiques à partir du milieu des années $1960^{152}$. Leurs travaux critiquaient en général le caractère répressif de l'État ou son incapacité à solder 
les comptes du passé nazi. En 1987, les manifestants hostiles au recensement ${ }^{153}$ diffusèrent ainsi le graphisme "L'aigle fédéral embrasse l'aigle nazi » réalisé quelques années plus tôt par un étudiant en arts plastiques, Urban Müller ${ }^{154}$. En sens inverse, un timbre de 1987 présentait le recensement sous forme de points noirs, jaunes et rouges formant un aigle fédéral ${ }^{155}$. Il s'agissait d'exploiter une image qui avait commencé à faire son chemin : l'association de l'aigle fédéral aux libertés constitutionnelles.

La réunification marqua néanmoins la fin d'un cycle. À cette date, le sentiment d'unité s'exprima à travers les couleurs noir-rouge-or, comme en témoignaient les drapeaux troués brandis par les manifestants de RDA. Les générations éduquées en RDA n'avaient pas de raison de s'attacher à un symbole moins visible que les couleurs communes aux drapeaux des deux pays. Une évolution similaire était à l'œuvre en RFA, ce que confirme l'analyse des timbres-postes. Avant 1980, l'aigle était plus sollicité que les couleurs noirrouge-or ; le rapport s'équilibra dans les années 1980, et à partir de 1990, ce sont les trois couleurs qui dominent ${ }^{156}$.

Les communistes polonais, eux, utilisèrent l'aigle pour renouer avec la tradition démocratique polonaise. D'où l'adoption de la version découronnée dès 1943, tant par les détachements de partisans de la garde populaire que par la division Kościuszko formée en URSS $^{157}$. Les blindés polonais combattant sur le front de l'est étaient ainsi identifiables à l'aigle de leurs tourelles. Les premières émissions de timbres témoignaient de l'image qu'entendait donner le nouveau régime. Trois thèmes peuvent être identifiés : la tradition insurrectionnelle et démocratique polonaise (Traugutt, Kościuszko, DĄbrowski ${ }^{158}$ ), le sentiment antiallemand (monument Grunwald de Cracovie ${ }^{159}$ ) et avant tout la souveraineté retrouvée (aigle polonais démocratique accompagné d'inscriptions commémoratives $)^{160}$. La mise en avant de symboles patriotiques allait au devant des attentes de la population, en donnant l'impression d'un retour à la normale après plusieurs années d'une occupation visant à détruire l'identité polonaise. Elle s'efforçait également de contrebattre les arguments de ceux qui considéraient le régime comme étranger ${ }^{161}$. Aussi la Pologne fut-elle l'une des rares démocraties populaires à inscrire ses armes dans une continuité nationale et historique.

L'apogée du stalinisme marqua un net recul de l'usage des symboles nationaux; entre 1949 et 1955, la poste polonaise privilégia les références au plan de six ans, au prolétariat ou à la colombe de la paix. L'aigle, quasiment banni entre 1949 et $1953^{162}$, fit une timide réapparition durant la période de "petite stabilisation » (1954-1956), plus nettement par la suite. La production postale permet de dégager trois axes de l'iconographie aquiline du régime. L'un d'eux a trouvé son expression la plus caractéristique dans le monument de Bohdan Chmielewski dédié aux « morts tombés au service et pour la défense de la Pologne populaire $»^{163}$, inauguré à Varsovie en 1985 . Cet ensemble, haut de seize mètres et large de vingt, représentait des soldats et miliciens veillant sur des hommes et femmes, ouvriers, paysans et membres de l'intelligentsia occupés à hisser un aigle sans couronne au sommet d'un pilier ${ }^{164}$. L'aigle incarnait ici la Pologne populaire, comme dans $9 \%$ des éditions de timbre portant un aigle émises entre 1954 et 1989. Une proportion équivalente associait l'aigle aux " terres recouvrées ", c'est-à-dire aux territoires pris sur l'Allemagne à l'issue de la Seconde Guerre mondiale. Dans ce cas, la mise en évidence de l'aigle des Piast, en particulier en Silésie, permettait de souligner les droits historiques dont se réclamait la Pologne populaire. L'armée populaire et les traditions militaires nationales formaient le troisième thème (pas moins de $42 \%$ des cas, dont un tiers de composition dominées par l'aigle et une moitié où il n'était qu'un détail). 
Ces efforts de propagande n'empêchèrent pas des visions concurrentes de circuler. Le gouvernement en exil était resté fidèle à l'aigle de l'Entre-deux-guerres. En Pologne même, le millénaire du baptême de Mieszko Ier en 966 donna lieu à une intense rivalité entre les deux institutions qui se posaient en seules garantes de l'authenticité nationale : l'Église catholique et le gouvernement. L'aigle fut alors souvent peint ou sculpté dans les églises, en rappel d'un baptême qui, selon la grille de lecture catholique, liait indissolublement identité polonaise et religion. L'église Saint-André Bobola de Saska KĘpa à Varsovie est un bon exemple de cette production iconographique. Au sommet de l'arc cintré surmontant l'autel, entouré des saints nationaux, se trouve le blason polonais ${ }^{165}$ surmonté du monogramme marial et d'une couronne. Il s'agissait d'une allusion claire au vaste programme décennal d'évangélisation centré sur la dévotion à la Vierge de CZĘstochowa reine de Pologne, lancé par le cardinal Wyszyfski en 1956. Cette iconographie a continué à se développer après la chute du communisme. On a ainsi inauguré en novembre 2008 dans l'église du Christ-Roi du quartier varsovien de Targówek une « chapelle» - parler d'autel latéral serait plus exact - du «miracle de la Vistule » ${ }^{166}$. Un aigle polonais doré y survole une urne contenant de la terre du cimetière de Radzymin où reposent des soldats décédés en 1920 lors de la bataille de Varsovie. Une grande mosaïque murale de la Vierge victorieuse veille sur le tout, tandis que l'inscription « Deo et Patria » inscrit la bataille dans la vision catholique de l'histoire.

L'aigle polonais fut également mobilisé par les opposants au régime. Durant l'état de guerre, jouant de la ressemblance entre le mot wrona (corneille) et le sigle WRON désignant le Conseil Militaire de Salut National ${ }^{167}$ institué par Jaruzelski, ils scandaient que « la corneille ne vaincra pas l'aigle ${ }^{168}$. Les tracts et affiches recueillis par l'institut Karta ${ }^{169}$ témoignent d'un fréquent recours à l'aigle, toujours couronné et souvent accompagné de symboles religieux ${ }^{170}$. Il incarnait l'authenticité nationale face au pouvoir disqualifié comme étranger.

\section{Aigles polonais et allemands dans la société actuelle}

La chute du communisme n'a pas altéré la popularité de l'aigle, auquel s'identifient volontiers les Polonais. Son image est sollicitée par les publicitaires : Orlen, la plus grande firme pétrolière du pays a ainsi choisi l'aigle pour logo, et pour slogan un énigmatique « la qualité de l'aigle » ${ }^{171}$. L'intérêt des Allemands pour leur aigle est moindre : celui-ci est légèrement moins présent sur Internet que son homologue polonais, alors que l'on compte près de trois Allemands pour un Polonais usager de ce media ${ }^{172}$. Une recherche conduite en utilisant les versions allemandes et polonaises de Google le 13 juillet 2010 donnait environ 72500 réponses pour «Bundesadler », 24800 pour « Reichsadler » et 116 000 - un chiffre en forte croissance par rapport au début de l'année ${ }^{173}$ - pour " Orzeł Biały $»$ (respectivement 7 690, 8980 et 7940 en mode graphique $)^{174}$. L'aigle polonais n'est pas uniquement plus populaire : il fait aussi plus consensus que l'aigle allemand. Un certain nombre de sites consacrés à l'aigle impérial, notamment ceux qui proposent des vêtements floqués à son image, vouent un culte nationaliste à l'aigle impérial.

La comparaison de l'espace public des deux pays confirme cette impression. L'aigle polonais y est largement représenté. Il continue à être un symbole de la souveraineté polonaise et de la lutte de la nation pour son État. Il figure à ce titre dans plusieurs monuments récents, par exemple dans le «Monument de Józef Piłsudski et de l'action indépendantiste $»^{175}$ de Czesław Dêwigaj inauguré le 10 novembre 2008 à Cracovie. De 
toutes ces réalisations, l'une des plus intéressantes est le « Monument de l'État polonais clandestin et de l'Armia Krajowa » réalisé par Mariusz Kulpa et inauguré à Poznań en 2007. Il concentre en effet la plupart des symboles récents de la lutte pour l'indépendance: l'ancre, symbole de la Pologne combattante, l'aigle polonais et même l'insurrection de Varsovie ${ }^{176}$ évoquée par une bouche d'égout ${ }^{177}$. L'aigle est la figure-clef de cette composition, centrée sur une pyramide-cage à moitié enterrée, entourée de colonnes évoquant les faits d'arme de l'Armia Krajowa. Il orne, sous forme héraldique, l'un des versants de la pyramide. Il symbolise surtout la liberté retrouvée, puisque la sculpture décompose les différentes phases de son envol hors de la pyramide.

L'aigle polonais décore également des tombes d'anciens combattants des cimetières de Powàzki, à Varsovie ; il agit en marqueur, identifiant les personnes ayant contribué de manière importante à la cause indépendantiste polonaise. Cette tradition remonte au moins aux années 1920, avec la tombe de Zbigniew Stroynowski, décoré de la Virtuti Militari et décédé lors de la bataille de Varsovie le 17 ou 18 août 1920. Elle avait été reprise par l'armée populaire polonaise : la tombe du général Aleksander Waszkiewicz, décédé en avril 1945, associe à l'aigle polonais une inscription bilingue (Waszkiewicz était un officier biélorusse de l'Armée rouge délégué auprès de l'armée polonaise). Parmi les sépultures récentes, citons celle de l'aviateur Stanisław Skarski ou celle d'Antoni Pajdak et Jerzy Âmiechowski ; l'aigle y côtoie l'ancre de la Pologne combattante.

Il est beaucoup plus difficile de trouver des tombes allemandes analogues ${ }^{178}$, ce qui peut néanmoins tenir à des traditions différentes (les tombes berlinoises étant bien plus sobres que celles de Varsovie). En revanche, l'aigle allemand est à coup sûr peu sollicité par l'art monumental contemporain. Lorsqu'il l'est, c'est pour être associé, aux valeurs démocratiques, d'où la mise en avant de la "fette Henne ». C'est elle que Herbert Fell a mobilisée pour ses happenings. Cet artiste a crée un «Parc de sculptures de l'unité allemande » (Skulpturenpark deutscher Einheit) dans la zone de la mort du rideau de fer, à Mellrichstadt, en Basse-Saxe. Lors de l'action incendiaire du 9 novembre 1999, un aigle en bois a été brûlé; des cendres a émergé l'aigle de Gies ${ }^{179}$. Cette allusion à l'incendie du Reichstag reprenait l'image démocratique de l'aigle de 1953, opposé à l'aigle impérialiste. Dans cette perspective, le retour des députés à Berlin marquait la fin d'un demi-siècle de totalitarisme inauguré par la prise de pouvoir d'Hitler.

L'expérience de la Seconde Guerre mondiale reste centrale lorsqu'il s'agit de saisir les différents rapports qu'entretiennent les sociétés allemandes et polonaises par rapport à leur symbole national. Dans un cas, l'expérience de la résistance a poussé à son paroxysme l'identification de l'aigle à la survie d'une nation polonaise. Dans l'autre, c'est une logique d'identification de l'aigle à des visées impérialistes qui a été poussée à terme, au point de couvrir le symbole d'un opprobre qu'il a été difficile de lever. Plus fondamentalement, l'expérience du $\mathrm{XIX}^{\mathrm{e}}$ siècle, particulièrement durant la phase d'« invention des traditions » nationales, a affecté aux aigles allemands et polonais des contenus sensiblement différents. Durant les siècles précédents, la spécificité impériale de l'aigle allemand avait certes entraîné des déplacements d'accent par rapport au cas polonais, mais les fonctions remplies par ces deux symboles restaient suffisamment proches pour que l'on note des emprunts à la culture impériale dans la Pologne-Lituanie. Une étude plus approfondie de la réception sociale de ce symbole, ainsi que de ses relations avec d'autres signes utilisés pour représenter l'État, doit néanmoins être entreprise pour permettre d'en savoir plus. 
NOTES

1. Marek Czaplinski, Hans-Joachim Hahn, Tobias Weger (dir.), Schlesische Erinnerungsorte. Gedächtnis und Identität einer mitteleuropäischen Region. Eine Veröffentlichung des Schlesiens Museums zu Görlitz, Görlitz : Neisse-Verlag, 2005.

2. Jacques Le Rider (dir.), Transnationale Gedächtnisorte in Zentraleuropa, Innsbruck/ Wien/ München/ Bozen: Studien-Verlag, 2002. En septembre 2010 se tiendra à Augustów une conférence sur le thème des lieux de mémoire des nations d'Europe de l'Est.

3. Le projet est dirigé par Hans Henning Hahn (Université d'Oldenbourg) et Robert Traba (Centre de Recherche Historique berlinois de la PAN) en collaboration avec Maciej Górny et Kornelia Kofczal (tous deux du Centre de Recherche Historique berlinois de la PAN).

4. Pour limiter le risque d'hétérogénéité, les contributions des auteurs ont également été passées au crible avant même la phase de rédaction. La conférence de Słubice, en mai 2008, a donné le coup d'envoi d'un long travail préparatoire, dont le calendrier est disponible sur le site du projet. Depuis cette date, chaque auteur a présenté les grandes lignes de sa contribution lors de l'une des sessions préparatoires tenues tous les six mois. Les présentations, d'une vingtaine de minute, étaient suivies d'une discussion d'environ quarante minutes. Les instructions envoyées aux auteurs, elles, leur rappelaient la nécessité de ne pas s'en tenir à un cadre national pour prendre en compte les dimensions sociales, régionales, confessionnelles ou de genre de la mémoire.

5. La réflexion a avancé au rythme de deux sessions par an. Les premières rencontres ont permis de préciser les concepts et de proposer une liste de lieux de mémoire. Cette réflexion s'est révélée si riche que les trois tomes de la publication principale vont être enrichis par des publications visant à faciliter les transferts intellectuels. Seront ainsi publiés : une anthologie de textes polonais (un tome, en allemand) et une autre de textes allemands et occidentaux (deux tomes, en polonais) sur la culture de la mémoire, une anthologie de textes sur les notions de mémoire collective et de lieux de mémoire, et enfin un dictionnaire interdisciplinaire Modi memorandi.

6. Les sociologues polonais se sont intéressés relativement tôt à la mémoire, mais les pistes ouvertes il y a quelques décennies n'ont pas débouché sur un essor de «l'histoire au second degré ». Même l'article précoce (1982) du sociologue Andrzej Szpocifski, qui participait au séminaire de Pierre Nora, n'a pas permis de susciter une tradition de recherche contemporaine: Andrzej Szpocifski, «Kanon historyczny» [Le canon historique], Studia socjologiczne, n. 91 (1983), cité par Robert Traba, Maciej Górny, Kornelia Kofczal, «Deutsch-polnische Erinnerungsorte. Polsko niemieckie miejsca pamiĘci. Reinterpretacja i nowa koncepcja badaf ", article distribué aux participants des ateliers de travail de Słubice, mai 2008, p. 22.

7. Moritz Csáky, «Die Mehrdeutigkeit von Gedächtnis und Erinnerung. Ein kritischer Beitrag zur historischen Gedächtnisforschung ", Digitales Handbuch zur Geschichte und Kultur Russlands und Osteuropas, p. 4, 10-11. http://epub.ub.uni-muenchen.de/603/1/ csaky-gedaechtnis.pdf (25 juin 2010).

8. Ibid, p. 8.

9. Ibid, p. 16.

10. On avait reproché à par Pierre Nora d'avoir réuni une équipe exclusivement française. Les auteurs allemands avaient, eux, fourni $80 \%$ des contributions des Deutsche 
Errinerungsorte. R. Traba, M. Górny, K. Kofczal, « Deutsch-polnische Erinnerungsorte ... », p. 18 suiv. Les efforts entrepris pour intégrer des historiens non allemands ou polonais au projet ont cependant buté sur des contraintes linguistiques (nécessité de maittriser deux langues étrangères). $91 \%$ des auteurs viennent de Pologne ( $50 \%$ ou d'Allemagne (41\%). La France vient en troisième position ( $5 \%$ ) devant l'Italie (2\%), la République tchèque et la Suisse (1\%). Par contre, neuf disciplines scientifiques sont représentées (sans compter les auteurs journalistes), de l'histoire qui se taille la part du lion (61\% des auteurs) à la musicologie. L'histoire de l'art est sous-représentée (1\% des auteurs seulement), tandis que les études littéraires (Literaturwissenschaft) arrivent en bonne position (19\%). Kornelia Kofczal, $\quad$ http://www.cbh.pan.pl/index.php? option=com_content\&view=article\&id=46\&catid=21\&Itemid=136\&lang=de (23 juin 2010).

11. Pierre Nora avait négligé certains thèmes (immigration, colonisation) parce que sa démarche initiale rappelait celle des folkloristes. Comme Van Gennep jadis, il entendait dresser l'inventaire d'une culture historique républicaine et nationale en voie de disparition depuis les années cinquante. Son projet a été ensuite élargi, non sans un certain empirisme quant au concept de lieux de mémoire. R. Traba, M. Górny, K. Kofczal, «Deutsch-polnische Erinnerungsorte ... », op. cit., p. 14 suiv.

12. La liste des thèmes retenus et rejetés est accessible à l'adresse internet mentionnée plus haut, note 10.

13. Sont retenus les titres allemands ; l'équivalent polonais n'est précisé que lorsqu'il s'agit d'un concept différent, suggérant une lutte mémorielle.

14. Le titre de la version actuelle du projet est d'ailleurs susceptible de froisser bien des Polonais, dans la mesure où ceux-ci se battent pour rappeler que "tout a commencé à Gdańsk », comme l'énonçait une campagne publicitaire diffusée en 2009. Or on a retenu ici un ordre non chronologique,...

15. La Shoah a occupé une place spécifique dans la culture mémorielle de la Pologne populaire, compte tenu d'une certaine rivalité polono-juive visant à obtenir le monopole du martyrologe

16. Notre Pape.

17. La confédération de Targowica fut formée à l'instigation de Catherine II par des nobles polonais hostiles à la constitution polonaise du 3 mai 1791. Son action conduisit au Deuxième partage de la Pologne.

18. Orzeł biały - 700 lat herbu pafstwa polskiego. 26 czerwca-15 paêdziernika 1995, Zamek królewski w Warszawie, Varsovie : Polskie Towarzystwo Heraldyczne, 1995.

19. Stefan Kuczynski (dir.), Orzeł Biały, herb pafstwa polskiego. Materiały sesji naukowej w dniach 27-28 czerwca 1995 na Zamku Królewskim w Warszawie, Warszawa : DIG, 1996.

20. Aleksandra Jaworska, Orzeł biały. Herb pafstwa polskiego, Warszawa : DIG, 2003.

21. Bettina Pferschy-Maleczek, «Der Nimbus des Doppeladlers. Mystik und Allegorie im Siegelbild Kaiser Sigmunds » in: Zeitschrift für historische Forschung, 4, 1996, p. 433-471; Claus Bleisteiner, « Der Doppeladler von Kaiser und Reich im Mittelalter. Imagination und Realität » in : Mitteilungen des Instituts für Österreichische Geschichtsforschung, 109, 2001, p. 4-52.

22. Johannes Enno Korn, Adler und Doppeladler, thèse, Götttingen, 1969.

23. Hans Hattenhauer, Deutsche Nationalsymbole. Geschichte und Bedeutung, Köln : Bundesanzeiger Verlag, 3e éd., 1998; Jürgen Hartmann, «Der Bundesadler» in: Vierteljahrshefte für Zeitgeschichte, 56, 2008, p. 495-510.

24. Matthias Puhle, Claus-Peter Hasse (dir.), Heiliges Römisches Reich Deutscher Nation 962-1806. Von Otto dem Grossen bis zum Ausgang des Mittelalters. Essays 29. Ausstellung des Europarates in Magdeburg und Berlin und Landesausstellung Sachsen-Anhalt, Dresden: Sandstein, 2006; Eid. (dir.), Heiliges Römisches Reich Deutscher Nation 962-1806. Von Otto dem Grossen bis zum Ausgang des Mittelalters. Katalog. 29. Ausstellung des Europarates in Magdeburg und Berlin und Landesausstellung Sachsen-Anhalt, 
Dresden : Sandstein, 2006 ; Heinz Schilling, Werner Heun, Jutta Götzmann (dir.), Heiliges Römisches Reich Deutscher Nation 962-1806. Altes Reich und neue Staaten 1495 bis 1806. Essays. 29. Ausstellung des Europarates in Magdeburg und Berlin und Landesausstellung Sachsen-Anhalt, Dresden: Sandstein, 2006 ; Hans Ottomeyer, Jutta Götzmann, Ansgar Reiss (dir.), Heiliges Römisches Reich Deutscher Nation 962-1806. Altes Reich und neue Staaten 1495 bis 1806. Katalog. 29. Ausstellung des Europarates in Magdeburg und Berlin und Landesausstellung Sachsen-Anhalt, Dresden : Sandstein, 2006. Pour la suite de l'article seront utilisés les raccourcis suivants: Von Otto dem Grossen ... Essays; Von Otto dem Grossen ... Katalog ; Altes Reich ... Essays et Altes Reich ... Katalog.

25. Petra Rösgen (dir.), Flagge zeigen? Die Deutschen und ihre Nationalsymbole. Begleitbuch zu Ausstellung im Haus der Geschichte der Bundesrepublik Deutschland, Bonn, 5. Dezember 2008 bis 13. April 2009, im Zeitgeschichtlichen Forum Leipzig der Stiftung Haus der Geschichte der Bundesrepublik Deutschland, 29. Mai bis 4. Oktober 2009, Bonn : Stiftung Haus der Geschichte der Bundesrepublik Deutschland, 2008, 168 p.

26. Ont été utilisés les catalogues de référence pour les timbres allemands (Michel) et polonais (Fischer). Les références numériques données en note de bas de page sont celles du timbre.

27. Le problème ne vient pas tant de l'exhaustivité ou non, mais du fait qu'il est par exemple difficile d'établir si des affiches forment un échantillon représentatif

28. Aleksandra Jaworska, Orzeł biały. Herb pafstwa polskiego, op. cit., p. 28.

29. Von Otto dem Grossen ... Katalog, p. 130.

30. J. E. Korn, op. cit., p. 47.

31. Le blason impérial (d'or à l'aigle de sable) vit le jour dans les années 1190. Otton de Freysing en fit la première description vers 1200. C. Bleisteiner, op. cit., p. 5.

32. Franz Heinz von Hye, « Neue Aspekten zur Geschichte des ein- und doppelköpfiger Adlers sowohl des Römisch-deutschen Königs, Kaisers und Reiches als auch Siziliens' « in : Stefan K. Kuczynski (dir.), L'aigle et le lion dans le blason médiéval et moderne. Actes du IXe colloque international d'héraldique. Cracovie, 4-8 septembre 1995, Varsovie: Académie internationale d'héraldique, Société polonaise d'héraldique, 1995, p. 86.

33. Ibid., p. 87.

34. Ryszard Kiersnowski y a vu successivement un coq, un paon puis un aigle, Rainer Sachs, une colombe. Z. Piech, « Wokół genezy orła białego jako herbu królestwa polskiego » in : Orzeł biały, op. cit. (voir plus haut, note 18), p. 18.

35. A. Jaworska, op. cit., p. 43.

36. C. Bleisteiner, op. cit., p. 5.

37. Cette monnaie peut être observée dans la riche catalogue en ligne du Staatliche Museum zu Berlin. http://www.smb.spk-berlin.de/ikmk/.

38. J. E. Korn, op. cit., p. 48.

39. Ibid., p. 50-51.

40. Von Otto dem Grossen ... Katalog, p. 282. http://www.smb.spk-berlin.de/ikmk/.

41. A. Jaworska, op. cit., p. 15 ; Z. Piech, op. cit., p. 23, suiv.

42. Ibid., p. 26.

43. Stanislas, évêque de Cracovie, fut exécuté en 1079 sur ordre du roi Boleslas II le Généreux.

44. Z. Piech, op. cit., p. 20, 26-27.

45. Z. Piech, op. cit., p. 30-31 ; A. Jaworska, op. cit., p. 54-58.

46. Z. Piech, op. cit., p. 32 ; A. Jaworska, op. cit., p. 60.

47. S. K. Kuczynski, « TreÊci i funkcje Orła Białego » in : Orzeł biały... op. cit. (voir plus haut, note 18), p. 34. 
48. Lieselotte E. Saurma-Jeltsch, «Zeichen des Reiches im 14. und frühen 15. Jahrhundert » in : Von Otto dem Grossen ... Essays, p. 338.

49. « eine beinahe totemistisch zu nennende Beziehung zum Adler » : Ibid.

50. Idem.

51. Ibid., p. 341-342.

52. Ibid., p. 340.

53. Przemysław Mrozowski, «O stylizacji Orła Białego w sztuce polskiej » in : Orzeł biały..., op. cit. (voir plus haut, note 18), p. 45.

54. Idem.

55. On peut trouver ce sceau, y compris avec un fort agrandissement, sur Internet, http:// dziedzictwo.polska.pl/katalog/skarb,odcisk,gid,110014,cid,177.htm

56. Aleksandra Jaworska, op. cit., p. 221.

57. http://dziedzictwo.polska.pl/katalog/skarb,,gid,387141,cid,178.htm

58. Aleksandra Jaworska, op. cit., p. 96.

59. Claus Bleisteiner, art. cit., 2001, p. 34.

60. Bettina Pferschy-Maleczek, art. cit., p. 459.

61. Le Buch der Heiligen Dreifaltigkeit, rédigé par un proche de l'entourage impérial, est typique de cette atmosphère intellectuelle: on y passe constamment du latin à l'allemand, de la langue courante à l'ésotérisme. Il est si déroutant qu'il a été qualifié d'œuvre de schizophrène lors d'une soutenance de thèse en 1986. Barbara Obrist en avait pourtant clarifié la teneur en 1982. Ce livre mystico-alchimique décrit le combat contre l'Antéchrist - le Hussite - comme un combat vers l'unité, entendue aussi bien comme enseignement du salut que comme recherche alchimique de la création d'or et d'argent. Considérant que toutes choses sont une dans la vérité, l'auteur désigne la même chose avec une quantité de concepts différents qui pour lui sont équivalents et interchangeables. Ibid., p. 453-454.

62. On en trouvera une reproduction dans Bettina Pferschy-Maleczek, op. cit., p. 458.

63. Ibid., p. 456-459.

64. La date d'adoption de l'aigle à deux têtes fait toujours débat. À l'encontre de la réalité, les milieux anglo-saxons en faisaient le blason impérial dès le XIII ${ }^{\mathrm{e}}$ siècle, selon une tradition inaugurée par les chroniques de Matthieu Paris. Selon Claus Bleisteiner, Paris aurait créé ces armes de fantaisie en appliquant le principe du dimidiating. Ce dernier consistait en la réunion de deux armes en une arme partie. L'aigle à deux-têtes serait ainsi né de l'addition de deux blasons mi-aigles. Op. cit., p. 9-11. Les premiers aigles à deux têtes apparurent dans l'entourage de l'empereur au milieu du XIV siècle. Un écu d'or battu vers 1338 est souvent invoqué pour avancer que l'empereur lui-même utilisait ce blason dès cette époque. Claus Bleisteiner rejette cette hypothèse : cette monnaie, qui rappelle d'autres écus battus à Anvers, pourrait provenir d'une contribution envoyée par Édouard III, vicaire impérial, à Louis de Bavière pour entrer en guerre contre les Valois. Quant à l'utilisation de plus en plus fréquente de ce symbole par la famille de l'empereur, notamment par Venceslas à Prague, Claus Bleisteiner y voit une volonté de distinguer son blason de celui du souverain. Op. cit., p. 20-22, 32-34, 40 suiv.

65. B. Pferschy-Maleczek, op. cit., p. 461 suiv.

66. Ibid., p. 455.

67. Von Otto dem Grossen ..., Katalog, op. cit., p. 453-454.

68. Altes Reich ... Katalog, p. 83-84.

69. Sven Lüken, « „Das Hailig Romisch Reich mit Sampt seinen Gelidern“ - Reichssymbolik und Reichsemblematik» in : Altes Reich ... Essays., p. 176 
70. Hans Burgkmair était lui-même auteur d'un célèbre aigle-quarteron. Ibidem.

71. Ibid., p. 42-43.

72. Stefan K. Kuczynski, «Treści i funkcje... », op. cit., p. 36. La copie numérisée de cet ouvrage peut être consultée sur le site de la Bibliothèque numérique polonaise (Polska Biblioteka cyfrowa).

73. Idem.

74. Bernd Roeck, « Die ästhetische Inszenierung des Reiches - Aspeckte seiner frühneuzeitlichen Ikonographie » in : Altes Reich ... Essays, p. 217.

75. Wojciech Jerzy Podgórski, « Nad nami Orzeł Biały ? Poezja polska wobec naczelnego symbolu Rzezcypospolitej » in : S. Kuczynski (dir.), Orzeł Biały, op. cit., p. 137.

76. Altes Reich ... Katalog, p. 344-345

77. Un premier Roland, en bois, avait été détruit en 1366 par les troupes de l'archevêque.

78. Selon Dieter Pötschke, les Rolands de Brème et du Brandebourg personnifiaient le droit impérial. "Ursprung und rechtliche Bedeutung insbesondere der märkischen Rolandsbilder ", Forum historice iuris, 1999. http://s6.rewi.hu-berlin.de/online/fhi/articles/9909poetschke.htm (28 $\mathrm{X} 2009)$.

79. Ibid.

80. L'aigle à deux têtes était également le symbole de Lübeck. Le succès de ces lustres reposait aussi sur l'association des registres locaux et impériaux. On retrouvait à la même époque d'autres facettes de ce patriotisme impérial à Hambourg, où l'on baptisa Leopold Primus l'un des deux vaisseaux de guerre construits en 1663-1669 pour protéger la flotte marchande. S. Lüken, « Das Hailig Romisch Reich ... », op. cit., p. 185.

81. Heiliges Römisches Reich Deutscher Nation 962-1806. Altes Reich und neue Staaten 1495 bis 1806. Katalog, op. cit., p. 87.

82. Sven Lüken, « Das Hailig Romisch Reich mit Sampt seinen Gelidern ». op. cit., p. 177.

83. Heiliges Römisches Reich Deutscher Nation 962-1806. Altes Reich und neue Staaten 1495 bis 1806. Katalog, op. cit., p. 91.

84. Ibidem.

85. A. Jaworska, op. cit., p. 261.

86. Orzeł Biały, op. cit. (voir plus haut, note 18), p. 95.

87. Ibid., p. 111.

88. Il s'agit d'un armorial assez populaire dans la noblesse polonaise du XVII ${ }^{\mathrm{e}}$ siècle.

89. Stefan Kuczynski, « „Orbis Polonus“ Szymona Okolskiego i frontispis Dawida Tscherninga » in : Zbigniew Bania et al., Podług nieba i zwyczaju polskiego. Studia z historii architektury, kultury i sztuki ofiarowane Adamowi Miłob'dzkiemu, Varsovie : PWN, 1988, p. 545-553.

90. Załosny Apollo nieczułych Polaków do łez pobudza nad zgubà Podola i Ukrainy, a do Marsa braç si' ka"e w anno 1673.

91. W. J. Podgórski, op. cit., p. 138-139.

92. Lament Orła polskiego nad herbowym W. Ks. L. Pogonià.

93. Lament Orła polskiego nad upadkiem ojczyzny.

94. W. J. Podgórski, op. cit., p. 141.

95. Stefan Kuczynski, « Orzeł Biały w powstaniach wyzwolefczych i ruchach wyzwolefczych XIX wieku » in : Id. (dir.), Orzeł Biały, op. cit., p. 241.

96. B. Roeck, op. cit., p. 222.

97. Andrzej Chwalba, Historia Polski 1795-1918, Kraków : Wydawn. Literackie, 2000, p. 150. 
98. La révision drastique des registres de noblesse visait aussi à aligner la structure sociale polonaise sur celle des voisins. Il y avait ainsi en 1797 quatre fois plus de nobles dans les terres acquises par le tsar lors des Partages que dans le reste du pays. Ibid., p. 81-82.

99. Tadeusz Jeziorowski, « Poczàtki polskiego orła wojskowego » in : S. Kuczynski (dir.), Orzeł Biały, op. cit., p. 195-198, 201.

100. Lech Trzeciakowski, «Poznań w dobie napoleońskiej. Pierwszy rok wolności » in : Kronika miasta Poznania, 1997, n³, p.65-103. Je remercie Benoît Roger qui m’a communiqué cette information.

101. Les couleurs nationales blanc et rouge furent adoptées plus tard, le 7 février 1831. S. Kuczynski, « Orzeł Biały w powstaniach... », op. cit., p. 245.

102. Ibid., p. 242-243.

103. « Polacy! To nasz Orzeł, ta ziemia jest nasza! » in : Ibid., p. 242.

104. « Za wolnoÊç Orła i Pogoni », Orzeł Biały..., op. cit. (voir plus haut, note 18), p. 168.

105. Ibid., p. 171.

106. Ibid., p. 333-336. Jerzy Borejsza possède ainsi une croix en cyrillique portant le sceau du gouvernement insurgé.

107. Orzeł Biały... op. cit. (voir plus haut, note 18), p. 336.

108. S. Kuczynski, « Orzeł Biały w powstaniach... op. cit., p. 248, 250-251.

109. Dans l'espoir d'étendre l'insurrection à la Ruthénie, on avait ajouté l'archange Saint-Michel à l'aigle et au cavalier. Ibid., p. 253-254.

110. «Nur [alter deutsche Reichsadler] [...] vereinigt in sich alle die deutsch-nationalen und historischen Beziehungen » : H. Hattenhauer, op. cit., p. 87.

111. Ibid., p. 88.

112. Hans Ulrich Thamer, « Das Heilige römische Reich als politisches Argument im 19. und 20. Jahrhundert » in : Altes Reich ... Essays., op. cit., p. 385-386.

113. Harald Lönnecker, « Rebellen, Rabauken, Romantiker. Schwarz-Rot-Gold und die deutschen Burschenschaften » in : P. Rösgen (dir.), Flagge zeigen ?, op. cit., p. 33.

114. " Das tausendjährige deutsche Reich hat 1806 durch einen gewaltsamen Stoss von Aussen geendet. Nichtsdestoweniger glaubt der Verfasser [...] noch heutzutage die Wappen des ehemaligen Heiligen Römischen Reichs und seiner Säulen, die Kurfürsten, als den Grundausdruck deutscher Grösse und Einheit setzen zu dürfen. Er hat auch die Zeit gewählt, in der Deutschland den Höhepunkt seiner Macht behauptete, die Zeit die sieben Kurfürsten »: Otto Titan von Hefner, « die Wappen der Souveräne der deutschen Bundesstaaten » in : Siebmacher's Wappenbuch, volume 1 : Die Wappen und Flagen die Herrscher und Staaten der Welt, 1858, reprint : Neustadt an der Aisch, 1978, p. 5.

115. H. Hattenhauer, op. cit., p. 90-91.

116. Heinrich A. Winkler, Histoire de l'Allemagne XIX ${ }^{e}-X X^{e}$ siècles. Le long chemin vers l'Occident, Paris : Fayard, 2005, p. 241.

117. Le Saint-Empire n'avait pourtant pas les faveurs de l'historiographie officielle, puisque Treitschke lui reprochait d'avoir empêché l'émergence d'un État allemand. H. U. Thamer, op. cit., p. 388-391.

118. «[...] aus dem deutschen Reiche ist ein Weltreich geworden ». Ibid., p. 391.

119. H. A. Winkler, op.cit., p. 239. La légende initiale parlait de Frédéric II. Les romantiques allemands firent de cette légende l'un des vecteurs de leurs aspirations nationales, en faisant de Frédéric Barberousse l'empereur endormi. Ce mythe réactualisé connut une telle popularité que l'organisation centrale des associations d'anciens combattants fondée en 1899 prit le nom de Kyffhäuerbund der Deutschen Landeskriegerverbände. K. Blaschke, "Kyffhäuser», Lexikon des 
Mittelalters, tome V, Munich, Artemis und Wikler, 1991, col. 1596. Gunther Mai, « Für Kaiser und Reich. Das Kaiser-Wilhelm-Denkmal auf dem Kyffhaüser » in : Id. (dir.), Das Kyffhaüser-Denkmal 1896-1996. Ein nationales Monument im europäischen Kontext, Köln/ Weimar/ Wien : Böhlau, 1997, p. 151, 154 suiv.

120. Guillaume II parada ainsi en costume teutonique à Marienbourg en 1902, appelant à une nouvelle guerre contre les Polonais: Danielle Buschinger, Mathieu Olivier, les Chevaliers teutoniques, Paris : Ellipses, 2007, p. 423.

121. Katechizm polskiego dziecka

122. Kto ty jesteś? //- Polak mały. //- Jaki znak twój ?//- Orzeł biały.

123. Damien Thiriet, « Le style Zakopane », http://www.normalesup.org/ dthiriet/

Zakopane/stylezakopane.html (17 juillet 2010).

124. Orzeł Biały... op. cit. (voir plus haut, note 18), p. 175.

125. «drobnà zmian'». Leszek Pudlowski, «Z najnowszych dziejów Orła Białego » in: Stefan Kuczynski (dir.), Orzet Biały, op. cit. (voir plus haut, note 18), p. 271.

126. «Z poczucia polskoÊci tak ju” „wyzwolony“ // e chciał Orła Polskiego pozbawiç korony ». La formule renvoyait aussi au parti agrarien de Thugutt, le PSL «Libération » (« Wyzwolenie ») : ibid, p. 272.

127. P. Mrozowski, op. cit., p. 52.

128. Fischer, p. 6-338.

129. Orzeł Biały... op. cit. (voir plus haut, note 18), p. 356

130. J. Hartmann, op. cit., p. 499.

131. Dorlis Blume, Ursula Breymayer, Ulrich Bernd (dir.), Im Namen der Freiheit! Verfassung und Verfassungswirklichkeit in Deutschland 1849 - 1919 - 1949 - 1989. Im Auftrag des Deutschen Historisches Museum, Dresden : Sandstein, 2008, p. 236.

132. Rainer Blasius, «Die Unwilligkeit zu singen. Deutschlandslied und Becher-Hymne zwischen Tradition und Neuenanfang, Verfremdung und Verschweigen » in : Flagge zeigen ?... op. cit., p. 75.

133. Son directeur, l'historien de l'art Edwin Redslob, considérait que l'aspect de l'aigle allemand devait être adapté aux fonctions que l'on entendait lui faire remplir. Aussi ne définit-on pas d'emblème officiel de la République. La RFA a hérité de cette tradition, ce qui fait dire à Jürgen Hartmann qu'il est plus facile de trouver des espèces d'aigles différentes dans le quartier gouvernemental de Berlin que dans un zoo : op. cit., p. 495.

134. Ibid., p. 500.

135. Échantillon d'affiches électorales trouvé sur internet (recherche « Wahlplakat DNVP » sur l'interface graphique de google.de, 11 juillet 2010).

136. Catalogue Michel, Deutsches Reich, p. 689-690.

137. Ibid., p. 769.

138. Ibid., p. 571-572.

139. Ibid., p. 529-537.

140. Ibid., p. 355-361

141. Ibid., p. 545.

142. Le premier timbre à l'effigie d'Adolf Hitler fut édité en 1937, mais à compter de cette date, $16 \%$ des éditions le représentèrent, toujours comme figure centrale de la composition. Ibid., p. 701-910.

143. Ibid., p. 565-863.

144. Ibid., p. 896.

145. Ibid., p. 906.

146. Ibid., p. 908. 
147. Thomas Petersen, «Zwischen Distanz und Akzeptanz. Nationalsymbole im Spiegel der öffentlichen Meinung » in : Flagge zeigen ..., op. cit., p. 56.

148. Christian Peters, « Die „Fette Henne“. Der Adler im Deutschen Bundestag », Ibid., p. 105.

149. L'architecte chargé de la rénovation du Reichstag Norman Foster n'était pas favorable au montage d'une reproduction de cette statue à Berlin, mais il dut s'incliner devant la volonté de la commission à la construction du Bundestag. Son président Dietmar Kansy affirma ainsi : «la grosse poule est pour ainsi dire notre Corporate Identity " (Die "Fette Henne» ist sozusagen unsere Corporate Identity). Ibid., p. 109.

150. Michel, Bundesrepublik Deutschland, 291.

151. Ibid., p. 781.

152. Björn Egging, « Korrekturen der Nationalfarben. Schwarz-Rot-Gold in der Kunst nach 1960 » in : Flagge zeigen ..., op. cit., p. 112 suiv.

153. Le formulaire de recensement suscita de telles protestations que l'opération dut être ajournée à plusieurs reprises. Les opposants craignaient que les données ne soient exploitées à des fins répressives. Le tribunal constitutionnel leur donna raison en ordonnant en 1983 la séparation des données privées de celles destinées à l'analyse statistique.

154. Bundesadler küsst die NS-Reichadler. Je remercie Angela Stirkel pour les informations communiquées autour de ce travail observé lors de l'exposition Flagge zeigen?

155. Michel, Bundesrepublik Deutschland, p. 1309.

156. Le rapport entre les éditions de timbres portant l'aigle et celles au noir-rouge-or est de 6 à 0 dans les années 1960, 7 à 5 dans les années 70, 12 à 13 dans les années 1980, puis 2 à 5 (années 1990) et 4 à 15 (2000-2008). Michel, Bundesrepublik Deutschland, p. 326-2708.

157. S. K. Kuczynski, « Treści i funkcje... », op. cit., p. 40.

158. Catalogue Fischer, Pologne, p. 339-341.

159. Ibid., p. 343.

160. Ibid., p. 342, 344-357.

161. Hanna Świda-Ziemba, Człowiek wewn'trznie zniewolony, Varsovie, ISNS UW, 2e édit., 1998, p. 125 suiv.

162. Seules quatre des 207 éditions de timbre émises alors comportaient un aigle (Fischer 516, $588,589,681$ ), et il s'agissait à chaque fois d'un détail de la composition. Fischer, Pologne, p. $492-698$.

163. "Poległym w stu"bie i obronie Polski Ludowej ».

164. http://www.sztuka.net/palio/html.run?_Instance=www.sztuka.net.pl\&_PageID $=857 \&$ newsId=10100\&_CheckSum=887744144 (13 juillet 2010). Ce monument été détruit en 1991 .

165. L'aigle polonais n'y est pas couronné, ce qui, sans présager d'un éventuel jeu avec la censure, semble être une référence au fait que la Pologne n'était pas un royaume en 966.

166. L'église elle-même est un ex-voto : sa construction fut motivée par la volonté de remercier Dieu pour cette victoire. http://www.chrystuskrol.pl/historia.html (13 juillet 2010).

167. Wojskowa Rada Ocalenia Narodowego. Zdzisław Zblewski, Leksykon PRL-u, Cracovie : Znak, 2000, p. 175.

168. «Orła wrona nie pokona!».

169. L'institut Karta collecte les fonds d'archives privés, en particulier ceux des milieux d'opposition.

170. http://www.karta.org.pl/archiwa_i_bazy_danych/Archiwum_Fotografii/49 (6 novembre 2009).

171. La première réponse obtenue en tapant « Orzeł Biały » sur google.pl le 13 juillet 2010 renvoie à Orzeł Biały S.A., entreprise spécialisée... dans le recyclage des batteries à plomb. 
172. Selon les statistiques du site Internet word stats, on comptait au 30 juin 201065123800 usagers d'internet en Allemagne et 22450600 en Pologne. http://www.internetworldstats.com/ stats9.htm (14 juillet 2010)

173. Une recherche similaire conduite le 26 janvier 2010 avait donné 69400 réponses pour « orzet biały ». Les statistiques allemandes sont restées stables durant ces six mois.

174. Recherche restreinte aux sites localisés en Allemagne et rédigés en allemand pour « Bundesadler » et "Reichsadler », aux domaines localisés en Pologne et écrits en polonais pour « Orzeł Biały ».

175. Pomnik Józefa Piłsudskiego i Czynu Niepodległościowego.

176. L'insurrection de Varsovie a été hissée au rang de lieu de mémoire polonais par excellence depuis l'inauguration d'un musée qui lui est dédié en 2004. Cela n'a pas été sans protestation, car cette insurrection faisait débat avant même d'éclater. Elle s'inscrivait en effet dans l'opposition entre deux conceptions du patriotisme. L'une, dite "romantique », privilégie la lutte armée. L'autre, dite "positiviste », née de l'échec du soulèvement de 1863, critique la lutte armée, accusée de saigner la nation et d'entraîner des répressions accrues, et privilégie un travail citoyen. Les héritiers de la première tendance exaltent l'héroïsme des insurgés de 1944 ; leurs adversaires acquiescent, pour ajouter aussitôt qu'on les a sacrifiés inutilement. On avait proclamé la mort du romantisme polonais dans les années 1990, il est revenu en force depuis, porté par cette mise en avant de l'insurrection de Varsovie. Les monuments qui lui faisaient référence étaient très rares hors de la capitale jusqu'à une époque récente, et ils étaient souvent liés à des Varsoviens réfugiés.

177. Les égouts ont été utilisés comme voie de liaison et d'évacuation par les insurgés. Andrzej Wajda en a donné une image saisissante dans son film Kanał (Ils aimaient la vie).

178. On ne trouve de tombe avec l'aigle allemand ni dans le Waldfriedhof Zehlendorf, ni dans le Dorotheenstädtischen Friedhof, deux des cimetières berlinois les plus célèbres.

179. http://www.skulpturenpark-deutsche-einheit.de/bundesadler.html (6 novembre 2009).

\section{AUTEUR}

\section{DAMIEN THIRIET}

Damien Thiriet est Maître de Conférences (Adiunkt) en histoire à l'Université de Cracovie ; il a été lauréat de la bourse Gabriel-Monod de la Mission Historique Française en Allemagne en 2009. 